\title{
From quality to outcomes: a national study of afterschool STEM programming
}

\author{
Patricia J. Allen ${ }^{1 *}$ D, Rong Chang ${ }^{2}$, Britt K. Gorrall ${ }^{2}$, Luke Waggenspack², Eriko Fukuda ${ }^{2}$, Todd D. Little ${ }^{2,3}$ and
}

Gil G. Noam ${ }^{1}$

\begin{abstract}
Background: State afterschool networks across the US are engaged in system-building efforts to improve the quality of science, technology, engineering, and math (STEM)-focused afterschool programming. This study examined national trends in STEM program quality, youth outcomes, and the connections between these two data sources.

Methods: One thousand five hundred ninety-nine youths (grades 4-12) enrolled in 158 STEM-focused afterschool programs across 11 state networks completed a retrospective self-assessment measuring STEM attitudes and socialemotional learning (SEL)/twenty-first-century skills. Two hundred fifty standardized observations of STEM activities were performed to measure STEM program quality.

Results: (1) Most youth (65-85\%) reported increases in STEM engagement, identity, career interest, career knowledge, relationships, critical thinking, and perseverance, with the largest gains reported by those engaging with STEM activities for 4 weeks or more; (2) there were significant, strong correlations between STEM and SEL/twenty-first-century outcomes reported by youth; and (3) youth participating in higher-quality STEM programming reported more growth than peers participating in lower-quality programs.

Conclusion: This effort demonstrates how investments in STEM program quality yield high returns for programs and youth and how collaborations between research and practice can track successes and challenges, determine investments in program management, and expand advocacy and policy efforts. Additionally, this study supports a growing body of literature that suggests a synergy between youth development and STEM learning approaches that can improve outcomes for youth.
\end{abstract}

Keywords: STEM, Afterschool, System-building, Quality, Social-emotional learning, Twenty-first-century skills

\section{Introduction}

This article introduces a national effort known as afterschool and science, technology, engineering, and math (STEM) system-building, which uses research-practice collaboration as a strategy to enhance informal STEM learning in children and adolescents across the United States (US) (Coburn \& Penuel, 2016). Recommendations made by the National Research Council in 2009, as well as the launch of the US federal government's "Educate to Innovate" campaign the same year, have led to significant investments to integrate both private and public sectors to support US STEM programs that meet afterschool, on the

\footnotetext{
* Correspondence: pallen@mclean.harvard.edu

${ }^{1}$ The PEAR Institute, McLean Hospital and Harvard Medical School, Belmont, MA, USA

Full list of author information is available at the end of the article
}

weekends, or during the summer (Bell, Lewenstein, Shouse, \& Feder, 2009; National Research Council, 2009; The White House, 2009). The goals of state afterschool network system-builders in many of the 50 US states are to help practitioners increase the quantity and quality of programming as well as to improve equity, diversity, access, and outcomes in STEM. Research is a key component of state system-building to gage the effectiveness of this work and to continuously improve efforts on local, state, and national levels. To understand whether the specific investments made in the system-building effort is improving quality of programming and STEM learning in young people, our cross-state research team worked with funders, state network leaders, program directors, educators, and students to measure STEM program quality and youth outcomes across the US. 
We begin by describing the state of STEM in the US and the ascent of afterschool in the educational landscape. We next describe the investments made to improve practice and support afterschool STEM programming and report the methods and results of the first systematic study of this national afterschool and STEM system-building effort. We conclude with a discussion of key findings, limitations, and recommendations based on the significant relationships found between STEM program quality and youth outcomes.

\section{The state of STEM in the US and the role of afterschool}

The US presents an interesting paradox between STEMrelated opportunity and attainment. Innovation drives the economy, and talent in the workforce drives innovation, but cultivation of STEM literacy, proficiency, mindset, identity, interest, and motivation in young people remains a challenge. Improving and expanding quality STEM education is considered a top priority in the US to foster innovative thinkers who can meet the demands of our increasingly STEM-focused world. Currently, STEM skills and experience are scarcer relative to workforce demands. For example, a recent analysis found that STEM positions, including jobs within computer and mathematical fields as well as life and physical sciences, are some of the most challenging to fill-often taking more than twice the duration than jobs in the transportation, legal, production, and construction fields (Rothwell, 2014).

Existing studies suggest that workforce challenges are a symptom of declining STEM attitudes and performance among children and youth in the US (OECD, 2015). The importance of positive STEM attitudes, including STEM interest, engagement, and identity, among others, is evidenced by studies of college course enrollment (Kidd \& Naylor, 1991), college major selection (Maltese \& Tai, 2011; Moakler \& Kim, 2014), college degree obtainment (Maltese \& Tai, 2010; Tai, Liu, Maltese, \& Fan, 2006), graduate school matriculation (Merolla \& Serpe, 2013), and career attainment (Stets, Brenner, Burke, \& Serpe, 2017; Venville, Rennie, Hanbury, \& Longnecker, 2013). The importance of STEM performance is evidenced by longitudinal studies that have found that STEM achievement in childhood predicts STEM achievement in adolescence (Morgan, Farkas, Hillemeier, \& Maczuga, 2016), that STEM career expectations in childhood predict future STEM degree attainment (Tai et al., 2006), and that STEM performance in mid- to late-adolescence directly affects students' intent to major in STEM (Wang, 2013). Given that STEM attitudes have been found to be key factors for increasing participation and persistence in STEM (Graham, Frederick, Byars-Winston, Hunter, \& Handelsman, 2013; Osborne, Simon, \& Collins, 2003), strategies that can improve STEM attitudes show promise for opening new pathways in STEM for all youth, especially low-income youth, youth of color, and girls, who disproportionately exit from STEM throughout school and college (Morgan et al., 2016).

Afterschool programs have emerged as key partners in STEM education to provide inspirational STEM enrichment opportunities that complement and supplement learning from the school day (Krishnamurthi, Ottinger, \& Topol, 2013). One of the defining qualities of afterschool is hands-on engagement, which can help bring STEM to life and inspire inquiry, reasoning, hypothesizing, experimenting, problem-solving, and reflecting on the value or importance of STEM in everyday life (National Research Council, 2015; Noam \& Shah, 2013). As of 2014, US afterschool programs are estimated to reach more than 10 million young people (Afterschool Alliance, 2014), including large numbers of traditionally underrepresented youth, underscoring the potential for afterschool settings to help narrow the STEM opportunity and achievement gaps. A recent study of 13,709 US households found that nearly $70 \%$ of parents reported that their child's afterschool program offers a STEM learning opportunity, and more than $50 \%$ of parents considered STEM as a factor when selecting a program (Afterschool Alliance, 2014).

Another advantage of STEM learning in afterschool is the emphasis the field places on fostering positive youth development (National Research Council, 2002; Noam \& Shah, 2014). Engagement of young people intellectually, academically, socially, and emotionally has been identified as one of the key criteria of programs that produce positive youth outcomes (National Research Council, 2009, 2015). Afterschool programs can increase engagement with STEM by coupling STEM concepts with interesting activities that foster youth voice and choice, build relationships with adults and peers, apply STEM to real-world social contexts, and support learning, thinking, interest, and identity development. This is important as studies have recently found that employers hiring for STEM jobs consider social-emotional learning (SEL) skills such as teamwork, collaboration, self-regulation, critical thinking, and problem-solving among the most important for making hiring decisions (Afterschool Alliance, 2017; The Business Roundtable,, and Change the Equation, 2014). SEL skills are referred to by many names, including twenty-first-century skills, workforce skills, life skills, essential skills, employability skills, noncognitive skills, or soft skills. For the purposes of the present paper, we refer to these broadly as SEL/twenty-first-century skills given the emphasis of afterschool programs on the development of SEL to impact all learning and performance on which twenty-first-century college, career, and life success depend (Pellegrino \& Hilton, 2012).

\section{Afterschool and STEM system-building research}

Recognizing the potential of afterschool to create opportunities for all young people to succeed in STEM, two 
private foundations have invested in a nationwide capacity-building project known as STEM systembuilding to improve the quality, quantity, and accessibility of STEM afterschool programs across the US. As of October 2017, all 50 US states have a statewide afterschool network, with 33 states also having either STEM system-building or planning grants (Mott Foundation and STEM Next, 2018). States receiving system-building support (1) engage key partners around a vision of quality STEM in afterschool, (2) map the existing landscape of afterschool and STEM efforts, (3) prioritize strategies and act to expand awareness of, supply of, and quality of STEM in afterschool through communication, policy, and professional development; and (4) measure the effectiveness of efforts (Mott Foundation and STEM Next, 2018). Networks are provided a process framework, a program quality framework, standards, concrete strategies, trainings, examples, and measurement tools to inform their work to improve and expand the quality of STEM-focused afterschool programs.

System-building states have increasingly focused on assessment of STEM-focused afterschool programs for a variety of practical reasons, including to support programs' continuous improvement efforts, to collect data to meet accountability requirements outlined in local and governmental policies, to show grant funders their return on investments, to advertise positive impacts of youth participation to the community, and to influence priorities for policymakers and other key educational stakeholders (Fredricks, Naftzger, Smith, \& Riley, 2017). Importantly, by coming together to form a nationwide network that implements common program quality standards and common measures (described below), the system-builders have made it possible to systematically collect data to track successes and challenges at the national, state, and local levels to inform the research and practice communities about levels of program quality and youth experiences based on a large and representative sample.

The present study describes the research design, methods, and results of this collective action-taken by funders, state network leaders, program directors, educators, and researchers-to measure national trends in the quality of STEM programming supported by state networks, national trends in the experiences of youth participating in programming, and the connections between the two sources of data. The study was specifically designed to examine whether quality of STEM activities or length of youths' involvement in programming increase STEM attitudes or SEL/twenty-first-century skills. This study builds upon the growing number of quantitative studies of program quality and youth attitudes conducted in afterschool settings, and the literature is briefly reviewed below.

\section{Review of research on STEM attitudes in afterschool settings}

Attitudes and beliefs about STEM have been primarily measured using self-report surveys, and while many have been developed and used in formal educational settings, fewer self-report surveys have been developed and validated to study attitudes of youth participating in afterschool programs and fewer studies have been conducted in afterschool/out-of-school time (OST) settings than in school settings. For instance, in an extensive literature review of peer-reviewed articles describing interest, motivation, and attitudes toward science and technology, Potvin and Hasni (2014) found that only 14 out of a total of 189 survey-based studies published between 2000 and 2012 specifically examined OST STEM opportunities (including summer camps, competitions, science fairs, and field trips). However, a growing body of literature indicates that participation in STEM-focused afterschool programs increases self-reported STEM interest, engagement, motivation, persistence, and identity (Chittum, Jones, Akalin, \& Schram, 2017; Dabney et al., 2012; Young, Ortiz, \& Young, 2017).

Interest in STEM-including career interest-and motivation have both been studied extensively, in large part because of their implications for encouraging more young people to pursue advanced levels of STEM education (Maltese \& Tai, 2010; Tai et al., 2006). For example, Tai et al. (2006) showed that an early interest in pursuing careers in the physical sciences or engineering was a stronger predictor of obtaining a college science degree than early academic achievement scores. A recent meta-analysis of 15 studies measuring STEM interest of youth participating in OST STEM activities (including afterschool and summer programs or clubs) found that OST programs had a small to medium positive effect on student interest in STEM (Young et al., 2017). Importantly, STEM interest is malleable and can be positively changed by afterschool programs. For instance, Chittum et al. (2017) found that fifth to seventh graders participating in a design-based STEM program (90 min per week for six to 12 weeks) that uses an inquiry-based approach reported significantly higher levels of science interest and competence than peers who did not participate.

Consistent engagement in afterschool STEM programming has also been shown to positively affect STEM career interest and participation in informal STEM activities (Chittum et al., 2017; Dabney et al., 2012; Sahin, Ayar, \& Adiguzel, 2013; Wulf et al., 2010; Young et al., 2017). For instance, Dabney et al. (2012) found that middle schoolers who regularly participated in science clubs and competitions or reported reading and watching science-related content were significantly more likely to endorse an interest in STEM-related careers in college than peers who did not participate in STEM. In many studies, participation and engagement are quantified based on the behavioral 
definition of engagement-such as by asking youth to rate how often they participated in science-/STEM-related activities outside of school. Few studies have examined the cognitive and emotional components of STEM engagement in afterschool settings (Martinez, Linkow, Velez, \& DeLisi, 2014).

STEM interest and engagement are closely linked to STEM identity development (Cribbs, Hazari, Sonnert, \& Sadler, 2015). A recent National Research Council (2015) synthesis report highlights the importance of a STEM learning identity and the role afterschool can play in its development. Existing studies of STEM identity in afterschool settings have primarily relied upon qualitative methods, such as interviews, observations, and analysis of youth notebook entries (Barton \& Tan, 2010; Tan, Barton, Kang, \& O'Neill, 2013; Wulf, Hinko, \& Finkelstein, 2013). These have found that STEM identity is strongly linked to the depth of learning and persistence in STEM, and students who come to value STEM and believe they can do STEM are more likely to report an interest in STEM careers (Aschbacher, Ing, \& Tsai, 2014). The development of STEM identity is viewed as an important factor in improving STEM participation among youth underrepresented in STEM. For example, Stets et al. (2017) found that science identity had a stronger influence on underrepresented college students' intent to move into science career after graduation than other factors such as science self-efficacy or academic performance.

\section{Review of research on STEM program quality in afterschool settings}

The literature on the assessment of STEM program quality in afterschool settings has been sparser than attitudinal studies. Program quality has been primarily measured using observation tools, and while many have been developed and used in formal educational settings (Bell et al., 2012), fewer quality observation tools have been developed and used to study the general quality of afterschool programs, such as the Youth Program Quality Assessment (YPQA) and Promising Practices Rating Scale (PPRS) (Naftzger, Sniegowski, Smith, \& Riley, 2018; Oh, Osgood, \& Smith, 2015). There are even fewer observation tools that have been designed specifically to measure the quality of afterschool STEM programming (Shah, Wylie, Gitomer, \& Noam, 2018).

The Dimensions of Success (DoS) (Shah et al., 2018) is one such quality observation tool that has been developed for STEM research and practice with funding from the National Science Foundation (NSF), with partners from Educational Testing Service (ETS) and Project Liftoff, and with guidance from leading informal science frameworks from the NSF and National Research Council (Friedman, 2008; National Research Council, 2009). DoS was validated to measure key indicators of afterschool STEM quality, including domains focused on STEM knowledge and practices (e.g., inquiry, content learning, reflection) and positive youth development related to STEM (e.g., relevance, relationships, youth voice) among others (Shah et al., 2018).

There are no studies, to our knowledge, that have examined the relationship between STEM program quality and youth outcomes in afterschool. However, theories of afterschool skill development and transfer suggest that high quality facilitation and content increases youth engagement (Fredricks et al., 2017). Additionally, for general (non-STEM) programs, higher afterschool program quality, measured using the Opportunities for Youth Agency subscale of the YPQA, was significantly related to higher levels of youth engagement at the end of program (Naftzger et al., 2018). Another recent study found that general afterschool program quality is related to positive outcomes such as pro-social behavior, intrinsic motivation, and concentration (Vandell, 2013).

\section{Research significance and aims}

This research builds upon existing studies and expands the scope and scale of research on STEM program quality and youth outcomes in several ways, including by increasing the generalizability of the findings with a representative sample of states, using tools validated in afterschool settings that measure indicators relevant to both STEM and youth development, and assessing STEM program quality and youth outcomes concurrently in the same sample of programs. The selection of a program quality tool took into consideration the availability of a validated, STEM-specific program observation tool that is in wide use across the systembuilding states-in this case, the DoS observation tool (Shah et al., 2018). The selection of a youth self-report survey took into consideration existing peer-reviewed literature as well as input from state networks and practitioners regarding outcomes that align with current programmatic goals and outcomes that are relevant across different types of STEM programming. With this in mind, the survey chosen assessed five STEM attitudes (i.e., STEM engagement, career interest and knowledge, activity participant, and identity) and four SEL/twenty-first-century skills (i.e., perseverance, critical thinking, relationships with adults, and relationships with peers) that are associated with success in STEM, both academically and professionally-and in this case, the survey was the Common Instrument Suite for Students (CIS-S, Little et al., 2019; Noam, Allen, Shah, \& Triggs, 2017; Sneider \& Noam, 2019).

Taken together, the aims of this multi-state study of afterschool STEM programming were to determine (1) how the quality of afterschool STEM programming varies within and across US states; (2) how youth outcomes vary within and across US states and whether student characteristics, such as gender, grade level, or race and ethnicity, influence youth outcomes; (3) how STEM 
attitudes relate to SEL/twenty-first-century skills that have been identified by employers as important for workforce success; and (4) how the quality of STEM activities relate to youth outcomes. Because the emphasis of the afterschool and STEM system-building initiative was on training and resources for programs and educators to improve the quality of STEM activities and because studies have linked general program quality with other positive outcomes among youth (Naftzger et al., 2018; Vandell, 2013), we hypothesized that participation in STEM-focused afterschool programs observed to have the highest levels of STEM quality would report the most gains in STEM attitudes and SEL/twenty-first-century skills. Additionally, because youth development philosophy is deeply embedded in afterschool programming, and because prior work has found connections between general program quality and youth agency (Naftzger et al., 2018), we hypothesized that the majority of programs would excel in youth development-related dimensions of quality, such as relationships and youth voice, and that there would be significant correlations between youth self-reported STEM attitudes and SEL/twenty-first-century skills.

\section{Methods}

This section describes the participants, measures, procedure, and data analyses used to examine national trends in youth outcomes, STEM program quality, and the connections between observation and survey data collected across 11 state system-building networks.

\section{Participants \\ Programs}

A total of 158 STEM-focused afterschool programs participated in the study (see Table 1 and the "Procedure" section for state selection). The programs represented a variety of settings, including school-based (69.8\%), community-based $(28.2 \%)$, or other $(2.0 \%)$, and program size ranged widely between three and 80 students (with an average of approximately 14 and a median of 20) based on the number of students observed participating in STEM activities. STEM facilitators had an average of 15.5 years of experience (a median of 8 years) working with students in afterschool settings, and more than half (64.2\%) had a college or graduate school degree. About one-half identified as belonging to groups traditionally underrepresented in STEM, specifically African American/Black (13.5\%) and Latino/a or Hispanic (38.5\%). Programs reported using diverse types of STEM curriculum or no curriculum at all-with answers ranging from very specific to broad in nature. Programs received varying levels of support from their network, such as coaching, training, technical assistance, and evaluation to support STEM teaching and learning, but the levels of support were not quantified.

\section{Students}

Data were collected from a total sample of 1599 students ( $45.8 \%$ female) in grades 4 to 12 who participated in an afterschool program that received support from one of

Table 1 Student demographics and sample sizes within the 11 state networks

\begin{tabular}{|c|c|c|c|c|c|c|c|c|c|c|c|}
\hline \multicolumn{2}{|c|}{ State information } & \multicolumn{2}{|c|}{ Sample sizes } & \multicolumn{8}{|l|}{ Demographics } \\
\hline \multirow[t]{2}{*}{ State \# } & \multirow[t]{2}{*}{ \# Prgms } & \multirow[t]{2}{*}{ CIS-S } & \multirow[t]{2}{*}{ Dos } & \multirow[t]{2}{*}{ Gender (\% F) } & \multirow[t]{2}{*}{ Race/ethnicity } & \multicolumn{6}{|c|}{ Grade (\%) } \\
\hline & & & & & & 4th & 5 th & 6th & 7th & 8th & 9th-12th \\
\hline 1 & 15 & 122 & 23 & 41.0 & 15.0\% AA/B; 3.7\% Al/NA; 0.9\% A/AA; 6.5\% L/H; 10.3\% MTO & 37.7 & 35.2 & 17.2 & 7.4 & - & 2.5 \\
\hline 2 & 12 & 137 & 19 & 47.4 & $\begin{array}{l}\text { 15.0\% AA/B; } 1.6 \% \text { Al/NA; 5.5\% A/AA; } 2.4 \% \text { L/H; 0.8\% ME/NA; } \\
\text { 3.1\% NA/PI; 10.2\% MTO }\end{array}$ & 15.3 & 10.2 & 39.4 & 23.4 & 10.2 & 1.5 \\
\hline 3 & 15 & 169 & 22 & 45.0 & $27.0 \% \mathrm{AA} / \mathrm{B} ; 2.8 \% \mathrm{Al} / \mathrm{NA} ; 8.5 \% \mathrm{~L} / \mathrm{H} ; 10.6 \% \mathrm{MTO}$ & 30.8 & 23.7 & 29.0 & 12.4 & - & 4.1 \\
\hline 4 & 14 & 90 & 27 & 40.0 & 25.0\% AA/B; 3.6\% A/AA; 20.2\% L/H; 1.2\% ME/NA; 4.8\% MTO & 28.9 & 32.2 & 13.3 & 6.7 & 3.3 & 15.6 \\
\hline 5 & 15 & 220 & 23 & 47.7 & $\begin{array}{l}\text { 13.7\% AA/B; } 1.6 \% \mathrm{Al} / \mathrm{NA} ; 5.5 \% \mathrm{~A} / \mathrm{AA} ; 28.6 \% \mathrm{~L} / \mathrm{H} ; 0.5 \% \mathrm{ME} / \mathrm{NA} \\
11.5 \% \mathrm{MTO}\end{array}$ & 20.0 & 15.9 & 33.6 & 21.4 & 7.7 & 1.4 \\
\hline 6 & 13 & 172 & 15 & 38.4 & $\begin{array}{l}40.4 \% \text { AA/B; } 0.7 \% \text { Al/NA; } 7.5 \% \text { A/AA; } 5.5 \% \text { L/H; } 2.7 \% \\
\text { NH/Pl; } 21.2 \% \text { MTO }\end{array}$ & 7.6 & 18.6 & 21.5 & 16.3 & 12.8 & 23.3 \\
\hline 7 & 8 & 99 & 11 & 46.5 & $\begin{array}{l}20.9 \% \mathrm{AA} / \mathrm{B} ; 1.1 \% \mathrm{AN} ; 8.8 \% \mathrm{Al} / \mathrm{NA} ; 1.1 \% \mathrm{~A} / \mathrm{AA} ; 11.0 \% \mathrm{~L} / \mathrm{H} ; \\
\text { 1.1\% NH/Pl; } 9.9 \% \mathrm{MTO}\end{array}$ & 7.1 & 7.1 & 44.4 & 17.2 & 17.2 & 7.1 \\
\hline 8 & 15 & 115 & 28 & 53.0 & $\begin{array}{l}\text { 10.0\% AA/B; } 0.9 \% \text { Al/NA; } 1.8 \% \text { A/AA; } 18.2 \% \text { L/H; } 0.9 \% \\
\text { ME/NA; 0.9\% NH/PI; } 10.0 \% \text { MTO }\end{array}$ & 15.7 & 18.3 & 26.1 & 29.6 & 9.6 & 0.9 \\
\hline 9 & 15 & 134 & 21 & 38.1 & $\begin{array}{l}\text { 4.5\% AA/B; } 1.8 \% \mathrm{Al} / \mathrm{NA} ; 2.7 \% \mathrm{~A} / \mathrm{AA} ; 37.3 \% \mathrm{~L} / \mathrm{H} ; 0.9 \% \mathrm{ME} / \mathrm{NA} ; \\
\text { 3.6\% MTO }\end{array}$ & 27.6 & 19.4 & 32.8 & 16.4 & 3.0 & 0.7 \\
\hline 10 & 20 & 161 & 37 & 51.0 & $\begin{array}{l}\text { 43.4\% AA/B; 1.3\% AN; 3.3\% A/AA; } 13.8 \% \text { L/H; 0.7\% ME/NA; } \\
\text { 9.9\% MTO }\end{array}$ & 14.3 & 22.4 & 21.1 & 26.1 & 9.3 & 6.8 \\
\hline 11 & 16 & 180 & 25 & 52.8 & 45.8\% AA/B; 0.6\% Al/NA; 0.6\% A/AA; 3.6\% L/H; 8.3\% MTO & 42.8 & 38.9 & 6.7 & 7.2 & 2.8 & 1.7 \\
\hline
\end{tabular}


the 11 state afterschool networks (see Table 1 and the "Procedure" section for state selection). Given that most programs served elementary and middle school students, high school students were combined to form a single group (grades 9-12). The sample was diverse and included groups that are historically underrepresented in STEM (Table 1). Across all 11 state networks, students identified as African American/Black (25.05\%), Alaska Native (0.21\%), American Indian/Native American (1.83\%), Asian/Asian American (3.11\%), Latino/a or Hispanic (13.90\%), Middle Eastern/North African (0.42\%), Native Hawaiian or other Pacific Islander (0.71\%), White/Caucasian (29.9\%), or "more than one group" (10.44\%). About one-tenth of students preferred not to answer. About onethird of students $(29.9 \%)$ reported speaking a language other than English at home. More than $60 \%$ of students reported participating in STEM programming for 4 weeks or longer. Based on the expected program enrollment provided by program directors, we estimate that approximately $16 \%$ of students opted out of assessment or were not present the day of assessment.

\section{Measures}

\section{Common Instrument Suite-Student (CIS-S)}

The CIS-S is a student self-report measure of five STEM attitudes and four SEL/twenty-first-century skills (see Table 2). Scales range from 5 to 10 items, but the number of items completed by students were reduced using a planned missing data design (see Table 2 and the "Procedure" section, below). While many of the items on the CIS-S give emphasis to general science, we report results as STEM outcomes broadly because the survey includes items that address all four domains that make up STEM and most programs facilitate activities that incorporate elements from two, three, or all four STEM domains. For example, "I am curious about...science," "I am curious about...technology," "I am curious about...engineering," or "I am curious about...math." The conceptualization and psychometric properties of this survey are described below. Additionally, scale definitions, item examples, number of items, and scale endpoints are described in Table 2.

Conceptualization of CIS-S scales STEM engagement. This construct was measured using the Common Instrument, a validated self-report survey of STEM engagement that was developed in partnership with researchers and practitioners in the informal STEM education field (Little et al., 2019; Martinez et al., 2014; Noam et al., 2017; Sneider \& Noam, 2019). This scale captures three aspects of engagement: behavioral (e.g., participating or involving oneself in STEM activities or projects), cognitive (e.g., to be drawn to understanding, observing, or figuring out STEM phenomena), and

Table 2 Domains, scales, definitions, and item examples for the common instrument suite—student survey

\begin{tabular}{|c|c|c|c|c|c|}
\hline Domain & Scale & Definition & Example item & \# items & Scale endpoints \\
\hline \multirow[t]{5}{*}{ STEM attitudes } & STEM engagement & $\begin{array}{l}\text { Interest and excitement in } \\
\text { participating in STEM }\end{array}$ & $\begin{array}{l}\text { "I like to participate in } \\
\text { science projects." }\end{array}$ & 10 & $\begin{array}{l}\text { Strongly disagree to } \\
\text { strongly agree }\end{array}$ \\
\hline & STEM career interest & $\begin{array}{l}\text { Motivation to pursue a } \\
\text { career in STEM }\end{array}$ & $\begin{array}{l}\text { "Science will help me } \\
\text { find a job." }\end{array}$ & 7 & $\begin{array}{l}\text { Strongly disagree to } \\
\text { strongly agree }\end{array}$ \\
\hline & STEM career knowledge & $\begin{array}{l}\text { Knowledge of STEM-related } \\
\text { careers and the steps to attain } \\
\text { them }\end{array}$ & $\begin{array}{l}\text { "I know about different } \\
\text { kinds of science jobs." }\end{array}$ & 4 & $\begin{array}{l}\text { Not informed at all to } \\
\text { very well informed }\end{array}$ \\
\hline & STEM identity & $\begin{array}{l}\text { Understanding of oneself as a } \\
\text { person who can do STEM and } \\
\text { be in STEM }\end{array}$ & $\begin{array}{l}\text { "I think of myself as a } \\
\text { science person." }\end{array}$ & 7 & $\begin{array}{l}\text { Strongly disagree to } \\
\text { strongly agree }\end{array}$ \\
\hline & STEM activity participation & $\begin{array}{l}\text { Pursuit of STEM activities in } \\
\text { everyday life }\end{array}$ & "I watch science TV shows." & 4 & Hardly ever to very often \\
\hline \multirow[t]{4}{*}{$\begin{array}{l}\text { SEL/twenty-first- } \\
\text { century skills }\end{array}$} & Relationships with adults & $\begin{array}{l}\text { Positive connections and } \\
\text { attitudes toward interactions } \\
\text { with adults }\end{array}$ & $\begin{array}{l}\text { "There are adults who are } \\
\text { interested in what I have } \\
\text { to say." }\end{array}$ & 4 & Not at all to almost always \\
\hline & Relationships with peers & $\begin{array}{l}\text { Positive and supportive social } \\
\text { connections with friends and } \\
\text { classmates }\end{array}$ & $\begin{array}{l}\text { "I have friends who care } \\
\text { about me." }\end{array}$ & 4 & Not at all to almost always \\
\hline & Perseverance & $\begin{array}{l}\text { Persistence in work and } \\
\text { problem-solving despite } \\
\text { obstacles }\end{array}$ & $\begin{array}{l}\text { "I keep working even if it takes } \\
\text { longer than I thought it would." }\end{array}$ & 4 & Not at all to almost always \\
\hline & Critical thinking & $\begin{array}{l}\text { Examination of information, } \\
\text { exploration of ideas, and } \\
\text { independent thought }\end{array}$ & $\begin{array}{l}\text { "I like to think of different ways } \\
\text { to solve a problem." }\end{array}$ & 5 & Not at all to almost always \\
\hline
\end{tabular}

Note: The present study used a 10-form planned missing data design for the CIS-S, which reduced the number of questions answered by each student to a total of approximately 30 items plus five student background questions. While many of the survey items emphasize general science, the scales are labeled as STEM outcomes broadly because the survey includes items that address all four domains that make up STEM, and most programs focused on more than one STEM domain 
emotional (e.g., feeling a sense of excitement about, and enjoyment of, STEM). Cronbach's alpha for this scale, among the group of students in the current study, was .928 for the retrospective pretest and .934 for the retrospective posttest.

STEM identity. Items to capture STEM identity were adapted from previously published surveys of math and science identity and focus on students' recognition of their role in STEM and students' confidence to do STEM (Aschbacher et al., 2014; Cribbs et al., 2015). The concepts of recognition and competence draw on extensive sociological and psychological literature regarding the development of one's sense of self. Briefly, recognition refers to how youth view themselves in relation to STEM as well as how they feel they are viewed by others (i.e., their parents, teachers, or friends) in relation to STEM. Competence refers to how well youth feel they can do and succeed in STEM or how they feel others view their ability to do and succeed in STEM. Cronbach's alpha for this scale, among the group of students in the current study, was .912 for the retrospective pretest and .910 for the retrospective posttest.

STEM career interest, career knowledge, and activity participation. Items for these scales were based on the 2006 Programme for International Student Assessment (PISA) survey (OECD, 2007), a rigorous and comprehensive assessment that reports a high degree of reliability and validity. Adaptations of the scales were made to address concerns about reading comprehension levels, given that the PISA survey was originally designed for youth age 15 . The three scales were conceptualized to capture students' participation in STEM-related activities (STEM activity participation) and students' intrinsic and instrumental motivation to learn STEM, which refer to the joy gained from the idea of pursuing STEM careers and the drive to pursue STEM careers or activities in everyday life based on their perceived usefulness and importance (STEM career interest and knowledge, respectively) (OECD, 2014). Cronbach's alpha for these three PISA-adapted scales, among the group of students in the current study, ranged from .805 to .860 for the retrospective pretest and .810 to .865 for the retrospective posttest.

SEL/twenty-first-century skills. Critical thinking, perseverance, relationships with adults, and relationships with peers are part of a longer assessment of SEL skills known as the Holistic Student Assessment, a validated survey that is primarily used in educational settings (Malti, Zuffianò, \& Noam, 2017; Noam, Malti, \& Guhn, 2012). These four skills, which overlap in the STEM and youth development literature, apply to a broad array of personal, academic, and work situations (Afterschool Alliance, 2017; Lyon, Jafri, \& St. Louis, 2012). Specifically, STEM learning often demands persistence through trial and error (perseverance), and youths' resilience in the face of failure is thought to be associated with greater confidence in one's own STEM ability as well as greater motivation to act in the pursuit of STEM-related academic and career goals (Graham et al., 2013). Additionally, STEM learning requires youths to respond to a variety of tasks, questions, problems, or challenges (i.e., evaluating theories, conducting investigations, forming hypotheses, and interpreting results) that require flexible thinking and creativity (critical thinking). Lastly, building a STEM identity and developing personal meaning with STEM are influenced by the availability and quality of relationships with mentors, teachers, facilitators, and role models (relationships with adults) as well as friends or teams of youth (relationships with peers) (Robnett \& Leaper, 2013; Tyler-Wood, Ellison, Lim, \& Periathiruvadi, 2012). Cronbach's alpha for these four scales, among the group of students in this study, ranged from .801 to .914 for the retrospective pretest and .807 to .903 for the retrospective posttest.

Previous psychometric work on the CIS-S The psychometric properties of the five STEM attitudes and four SEL/twenty-first-century skills, administered in retrospective format, were tested in two separate studies conducted by Price (2018a, b). For both studies, confirmatory factor analytic techniques within a SEM model were used to verify that scale items display acceptable fit (i.e., evidence of construct validity). Fit statistics used for evaluation of the quality of confirmatory factor model results included the model chi-square statistic, degrees of freedom and $p$ value, the root mean square error of approximation (RMSEA) and its 90\% confidence interval, and the comparative fit index (CFI). The criteria for judging the quality of the factor analytic results were a RMSEA of .08 or smaller (a value of zero is best) and a CFI of .93 or higher (maximum possible value is 1.0).

Each of the five STEM attitudes were analyzed based on separate random samples of students participating in afterschool STEM programming across four regions of the US (STEM engagement, $n=2100$; STEM career interest, $n=2029$; STEM career knowledge, $n=1653$; STEM activity participation, $n=1410$; STEM identity, $n=2055)$. The samples for the five scales were similar to the present study sample: youth ages 9 to 19, approximately $49 \%$ females, and demographically diverse, with more than half of the samples identifying as youth of color. Overall, results demonstrated good model fit. Internal consistency reliability estimates (coefficient alpha) ranged between 0.82 and 0.91 across sex and age groups, and there were excellent item-total correlation statistics revealing that the items adequately explained parts of the construct as intended (Price, 2018a). 
Each of the four SEL/twenty-first-century skills were analyzed using similar methods described above and were specifically based on one random stratified sample of students participating in school and afterschool programs across four regions of the US that were not necessarily STEM-focused ( $n=12,000$ for critical thinking, perseverance, relationships with adults, and relationships with peers). The sample for the four scales was similar to the present study sample: youth ages 9 to 19, approximately $52 \%$ female, and demographically diverse, with more than half of the sample identifying as youth of color. Similar to the STEM scales above, the results for the four SEL/ twenty-first-century skills demonstrated good model fit. Internal consistency reliability estimates (coefficient alpha) ranged between 0.74 and 0.85 across sex and age groups, and there were excellent item-total correlation statistics revealing that the items adequately explained parts of the construct as intended (Price, 2018b).

\section{Dimensions of success (DoS)}

DoS is an observation tool used to assess the quality of informal STEM programming, including afterschool and summer programs (Shah et al., 2018). The tool captures 12 dimensions of STEM program quality that are categorized into the four domains conceptualized by Shah et al. (2018) (see Table 3 and the "Conceptualization of DoS domains" section, below). Rigorous training and certification are required to perform DoS observations. Qualitative data from field notes are quantified by the observer using a standard rubric on a 4-point scale from low (1, evidence absent) to high (4, compelling evidence). The criterion threshold for quality is a rating of 3 (reasonable evidence) out of 4 per dimension. The conceptualization of STEM program quality domains and the psychometric properties of this observation tool are described below.

Conceptualization of DoS domains The DoS framework captures four domains of STEM program quality (see Table 3), specifically the following:

The Features of the Learning Environment (FLE) domain captures the logistics and preparation of an activity, whether the materials are appealing and appropriate, and how the learning environment creates a suitable space for informal STEM learning.

The Activity Engagement (ActEng) domain requires observers to describe how the activity engages students. For example, the dimensions examine whether or not all students have access to the activity, whether activities are moving toward STEM concepts and practices purposefully or superficially, and whether or not the activities are hands-on and designed to support students to think for themselves.

The STEM Knowledge and Practices (STEMKP) domain defines how informal STEM activities are helping youth understand STEM concepts, make connections, and participate in the inquiry practices that STEM professionals use, and determines whether students have time to make meaning and reflect on their experiences.

The Youth Development in STEM (YDSTEM) domain assesses how student-facilitator and student-student interactions encourage or discourage participation in STEM

Table 3 Domains, dimensions, and definitions of quality STEM programming for the Dimensions of Success (DoS) observation tool

\begin{tabular}{|c|c|c|}
\hline Domain & Dimension & Examples of quality \\
\hline \multirow[t]{3}{*}{ Features of the Learning Environment (FLE) } & Organization & $\begin{array}{l}\text { Materials available, logical sequence, flexibility, } \\
\text { smooth transitions }\end{array}$ \\
\hline & Materials & Appropriate and appealing \\
\hline & Space utilization & Conducive to STEM learning with minimal distractions \\
\hline \multirow[t]{3}{*}{ Activity Engagement (ActEng) } & Participation & Students doing activities, following directions \\
\hline & Purposeful activities & $\begin{array}{l}\text { Students understand activity goals and time is used } \\
\text { to support learning }\end{array}$ \\
\hline & Engagement with STEM & $\begin{array}{l}\text { Opportunities for hands-on activities so students do } \\
\text { the cognitive "minds-on" work }\end{array}$ \\
\hline \multirow[t]{3}{*}{ STEM Knowledge and Practices (STEMKP) } & STEM content learning & $\begin{array}{l}\text { Accuracy of content presented in activities and } \\
\text { evidence of student learning }\end{array}$ \\
\hline & Inquiry & $\begin{array}{l}\text { Students using inquiry practices of STEM professionals } \\
\text { (e.g., scientists, mathematicians, engineers) }\end{array}$ \\
\hline & Reflection & $\begin{array}{l}\text { Opportunities for students to reflect and engage in } \\
\text { sense-making about activities }\end{array}$ \\
\hline \multirow[t]{3}{*}{ Youth Development in STEM (YDSTEM) } & Relationships & $\begin{array}{l}\text { Degree of positive, respectful interactions among } \\
\text { students and facilitators }\end{array}$ \\
\hline & Relevance & $\begin{array}{l}\text { Students and facilitators explicitly connect activities to } \\
\text { real-world, other subjects, STEM careers, etc. }\end{array}$ \\
\hline & Youth voice & $\begin{array}{l}\text { Students' opinions and ideas are heard, and they have } \\
\text { opportunities to make decisions }\end{array}$ \\
\hline
\end{tabular}


activities, whether or not the activities make STEM relevant and meaningful to students' everyday lives, and how the interactions allow youth to make decisions and have a voice in the learning environment and community.

Previous psychometric work on DoS The psychometric properties of DoS were tested in two separate studies (Shah et al., 2018). For both studies, the validity argument was tested by examining the descriptive statistics to determine the use of the full scoring scale, internal consistency as measured by Cohen's kappa and interrater agreement levels between observer pairs scoring the same activity, and factor analysis to examine the factor structure of the 12 DoS dimensions, and a preliminary G-study analysis. Study 1 consisted of 284 observations of STEM activities conducted by 38 observers at 60 afterschool programs located in two US regions (i.e., Midwest, Northeast). Study 2 consisted of 54 observations of STEM activities conducted by 17 observers at 32 summer programs located in two US regions (i.e., Midwest, Northeast). Results found the inter-rater agreement for the twelve dimensions had Cohen's kappas ranging from .73 to .94 and percentage agreement ranging from 95 to $100 \%$ based on the current training and certification methods (Shah et al., 2018). Previous psychometric analyses have found DoS to have similar, and sometimes stronger, levels of agreement between raters than the agreement levels reported for observation tools used in studies in formal settings (Bell et al., 2014; Shah et al., 2018).

\section{Procedure}

\section{State network and program selection}

A total of 11 state afterschool networks were chosen to participate in this study based on the following: (1) the collection of participating states together reflect the demographic diversity of the US, including rural, suburban, and urban composition; (2) the state afterschool networks receive system-building support from the two funders, and (3) the state afterschool networks demonstrate prior experience and capacity to implement a large-scale and complex study within the designated study time frame of 12 weeks. At the time of this study, a total of 17 system-building networks were available for selection, and 11 networks were chosen based on regional representation and readiness and capacity to participate. An expert demographer served as consultant to inform on the choice of states to ensure the representativeness of the sample.

Leaders from each of the 11 state afterschool networks (see Table 1) consulted with the researchers to choose 15 afterschool STEM education programs that best represent the afterschool universe in their state, ensuring a variety of curricular offerings that are taught in different settings (e.g., school-based, community-based, or other), that range in level of formality, and that represent different demographics including age and race/ethnicity. The researchers provided program selection guidelines to networks to assist in the recruitment process. More than $80 \%$ of programs reported four or more STEM sessions per month, and most programs were ongoing throughout the academic year (August/September-May/June).

\section{Assessment administration}

The student assessment (CIS-S) was created using the Qualtrics platform and administered electronically using Wi-Fi-enabled tablets or computers during the last week of STEM programming. Programs were provided with a weblink and a unique set of identification numbers to ensure that all data were de-identified. Participation was voluntary and anonymous.

The CIS-S was completed in group settings and under careful adult supervision. Administration took approximately $15 \mathrm{~min}$. All attitudinal items on the student assessment were in retrospective pretest-posttest format (Little et al., 2019), and students' responses were recorded using a visual analog scale (VAS), a continuous scale of measurement. Each scale ranged from 0 (strongly disagree) to 99 (strongly agree), with a score of 49 representing the midpoint (neutral). Respondents were asked to rate each assessment item twice from two different frames of reference: first to consider how they would respond to each item "Before the program" and then to respond how they feel right now, "At this time." Students were provided with instructions and practice items at the start of the assessment. To help prime retrospective thinking, a calendar image was presented in the instruction block. This design is like the traditional pretest-posttest method in that change is calculated by subtracting ratings for "Before the program" from "At this time." To minimize assessment length for the students and to maximize the quality of data, a 10form planned missing data (PMD) design was used. A PMD design accounts for the reason why data are missing and allows for the incomplete data to be easily recovered through multiple imputation (Little, Jorgensen, Lang, \& Moore, 2014).

\section{Quality observations}

State network leaders worked with DoS-certified individuals within their states to coordinate program quality observations at each participating program to estimate program quality. DoS certification requires that individuals successfully complete 2 days of live webinar training, a calibration session (to demonstrate high levels of inter-rater reliability with a standardized set of video observation examples), and two practice field observations with feedback before approval for certification (Shah et al., 2018). Observers 
partnering with state networks were typically evaluators; the researchers were not involved in scheduling or observing programs across states but provided training and certification and consulted with networks to ensure fidelity to study design and observation guidelines. Observations were conducted on one to two occasions toward the middle to end of programming, depending on each program's STEM activity schedule and the ability of observers to commute to programs located across each state. Certified observers recorded field notes describing evidence of STEM learning during STEM activities for a minimum of $30 \mathrm{~min}$ (a maximum of $120 \mathrm{~min}$, depending on activity length). Field notes and quantitative ratings for each program were submitted by observers electronically using an online form, which were reviewed by researchers to ensure the data met the standards set by the research team (i.e., individuals submitting observations were currently certified, evidence for each dimension of quality was described with sufficient detail, quantitative rating assigned for each dimension was supported by qualitative evidence provided).

\section{Ethical approval}

All procedures were reviewed and approved by the institutional review boards at our research institutions.

\section{Data analysis}

To quantify change in students' attitudes from "Before the program" (retrospective pretest) to "At this time" (retrospective posttest), repeated-measures analysis of variance (ANOVA) tests were conducted using the retrospective pretest scores and posttest scores for the CIS-S as within-subjects factors and state, gender, grade, race/ethnicity, program duration, and community type (i.e., rural, urban, suburban) as between-subject factors. For race and ethnicity analyses, we used the survey categories African American/Black, Asian/Asian American, Latino/a or Hispanic, and White/Caucasian (non-Hispanic) and collapsed the remaining six categories into one that we labeled Other (see the "Students" section. Additionally, correlational analyses of CIS-S scales were performed using Pearson's correlation coefficient to examine the relationship between the five scales measuring STEM attitudes and the four scales measuring SEL/ twenty-first-century skills.

To examine the relationship between student outcomes (CIS-S) and STEM program quality (DoS), the KruskalWallis test was used as a one-way test of variance to compare the nine CIS-S scales across three levels of program quality (i.e., higher, average, and lower). Levels of STEM program quality were calculated based on a composite DoS score (i.e., sum of 12 dimension ratings of STEM quality across four domains, for each observation) and a domain score (i.e., sum of three dimension ratings of STEM quality per domain, for each observation). Composite scores were converted to $z$-scores using a standardization sample representative of US STEM-focused afterschool programs that were observed using validated methods $(n=354$ observations performed between 2013 and 2016) (Shah et al., 2018), and programs receiving scores that were one standard deviation above or below the standardization mean were designated as "higher quality" or "lower quality," respectively. The remaining scores within one standard deviation of the standardization mean were considered as "average quality." Note that program quality was categorized into three levels to assist state network leads, practitioners, and researchers interpret overall STEM program quality using a composite score (i.e., sum across all 12 dimensions) for research, evaluation, and continuous improvement purposes. Comparing local- and state-level results to current national-level data is important for understanding how programs are performing relative to others and also for identifying where the field is succeeding and where it needs to improve.

For all analyses, alpha was defined as $p<0.005$ given the sensitivity of $p$ values to large sample sizes. Post hoc analyses were performed using Tukey's honestly significant difference (HSD) test or Mann-Whitney $U$ tests, as appropriate. Effect sizes were calculated using Cohen's $d$ or partial eta squared $\left(\eta_{P}^{2}\right)$, as appropriate.

\section{Results}

This section describes the results for student outcomes, STEM program quality, the connections between student outcomes and STEM program quality, and the relationships between students' STEM attitudes and SEL/twenty-first-century skills.

\section{Student outcomes}

In the following section, we report the findings across the nine core CIS-S scales. Table 4 summarizes the results for the nine core CIS-S constructs across the 11 states.

\section{Overall student-reported changes}

STEM attitudes Youth who participated in STEM programs reported increases in all five STEM attitudes, including STEM engagement, career interest, career knowledge, activity participation, and identity (see Table 4, all $p$ 's $<0.001)$.

SEL/twenty-first-century skills Youth who participated in STEM programs reported increases in SEL/twentyfirst-century skills, including perseverance, critical thinking, and quality of relationships with adults and peers (see Table 4, all $p$ 's $<0.001$ ). 
Table 4 Mean $( \pm S D)$ change in retrospective pretest-posttest ratings for nine CIS-S scales with between-state comparisons

\begin{tabular}{|c|c|c|c|c|c|c|c|c|c|c|c|c|c|}
\hline \multirow[b]{2}{*}{ Variable } & \multicolumn{2}{|c|}{$\begin{array}{l}\text { Retro } \\
\text { pretest }\end{array}$} & \multicolumn{2}{|c|}{$\begin{array}{l}\text { Retro } \\
\text { posttest }\end{array}$} & \multicolumn{2}{|l|}{ Stat. } & \multirow{2}{*}{$\begin{array}{l}\text { Signif. } \\
p\end{array}$} & \multirow{2}{*}{$\begin{array}{l}\text { Effect } \\
\text { size } \\
d\end{array}$} & \multicolumn{3}{|c|}{ Proportion of changes } & \multirow{2}{*}{$\begin{array}{l}\text { Between-groups } \\
\text { States }\end{array}$} & \multirow{2}{*}{$\begin{array}{l}\text { Effect size } \\
\eta_{p}^{2}\end{array}$} \\
\hline & $\bar{M}$ & $\mathrm{SD}$ & $M$ & $\mathrm{SD}$ & $t$ & $\mathrm{df}$ & & & Pos. $(+)$ & Neut. (=) & Neg. $(-)(-)$ & & \\
\hline STEM engagement & 60.2 & 19.9 & 70.0 & 19.3 & 26.6 & 1598 & $<0.001$ & 0.50 & $77.5 \%$ & $3.5 \%$ & $18.9 \%$ & $1: 11^{*}$ & .017 \\
\hline STEM career interest & 51.0 & 22.0 & 59.9 & 21.9 & 25.3 & 1598 & $<0.001$ & 0.40 & $75.7 \%$ & $3.7 \%$ & $20.6 \%$ & $1: 11^{*}$ & .017 \\
\hline STEM career knowledge & 45.0 & 23.3 & 55.7 & 21.5 & 28.6 & 1598 & $<0.001$ & 0.49 & $79.7 \%$ & $3.1 \%$ & $17.1 \%$ & $\begin{array}{l}1: 3^{*}, 1: 5^{*} ; 1: 7^{*} ; 1: 11^{*} ; 2: 7^{*} ; \\
3^{*}: 9 ; 5^{*}: 9 ; 7^{*}: 9 ; 11^{*}: 9\end{array}$ & .028 \\
\hline $\begin{array}{l}\text { STEM activity } \\
\text { participation }\end{array}$ & 36.5 & 21.2 & 45.3 & 22.4 & 26.8 & 1598 & $<0.001$ & 0.40 & $76.7 \%$ & $3.5 \%$ & $19.8 \%$ & $1: 10^{*} ; 1: 11^{*} ; 6: 10^{*}$ & .018 \\
\hline STEM identity & 50.2 & 22.8 & 58.1 & 22.3 & 23.9 & 1598 & $<0.001$ & 0.35 & $73.1 \%$ & $4.0 \%$ & $22.9 \%$ & $1: 8^{*} ; 1: 11^{*} ; 8^{*}: 9 ; 9: 11^{*}$ & .019 \\
\hline Critical thinking & 68.3 & 19.6 & 77.1 & 17.0 & 23.6 & 1598 & $<0.001$ & 0.48 & $72.9 \%$ & $4.2 \%$ & $23.0 \%$ & $5: 10^{*} ; 5: 11^{*}$ & .020 \\
\hline Perseverance & 67.3 & 20.1 & 76.2 & 17.3 & 22.4 & 1598 & $<0.001$ & 0.47 & $72.4 \%$ & $4.8 \%$ & $22.8 \%$ & $1: 11^{*} ; 6: 10^{*}$ & .018 \\
\hline Relationships with adults & 64.2 & 19.7 & 71.7 & 18.4 & 20.7 & 1598 & $<0.001$ & 0.39 & $71.0 \%$ & $4.9 \%$ & $24.1 \%$ & $1: 10^{*} ; 1: 11^{*} ; 6: 10^{*} ; 6: 11^{*}$ & .025 \\
\hline Relationships with peers & 72.9 & 18.2 & 78.4 & 16.2 & 16.8 & 1598 & $<0.001$ & 0.32 & $64.5 \%$ & $5.3 \%$ & $30.2 \%$ & $8^{*}: 9 ; 9: 11^{*}$ & .017 \\
\hline
\end{tabular}

Note: Each survey scale ranged from 0 to 99 , with a score of 49 representing the midpoint. There were statistically significant differences between states for all nine CIS-S outcomes (all $p^{\prime} s<0.001$ and all $n^{\prime} s=1599$, see main text). For between-group differences column for the states, the asterisk $(*)$ denotes the state with the greater difference between the retrospective posttest and retrospective pretest based on Tukey's HSD (i.e., State $1^{*}$ :State 2 indicates that State 1 showed a significantly greater change relative to State 2 , whereas State 1:State2* indicates that State 2 showed a greater change relative to State 1 )

\section{Student group comparisons}

Gender There was a main effect of gender on self-reported relationships. Female students reported higher quality of relationships with adults $(F(1,1)=39.06, p<0.001)$ and relationships with peers $(F(1,1)=60.37, p<0.001)$ compared to male students. The effect size for the effect of gender on relationships was small $\left(\eta_{P}^{2}=0.004\right)$.

Grade Grade was not a significant factor for any of the CIS-S outcomes. There were no significant gender by grade interactions detected (n.s., all p's >0.05).

Race and ethnicity There was a main effect of race and ethnicity for several outcomes, including four STEM attitudes-STEM engagement $(F(1,4)=6.87, p<0.001$, $\left.\eta^{2}=0.008\right)$, career interest $(F(1,4)=11.63, p<0.001$, $\left.\eta^{2}=0.014\right)$, career knowledge $(F(1,4)=15.12, p<0.001$, $\left.\eta^{2}=0.018\right)$, and STEM identity $(F(1,4)=17.92, p<.001$, $\left.\eta^{2}=0.021\right)$-and two SEL/twenty-first-century skillscritical thinking $\left(F(1,4)=9.37, p<0.001, \eta^{2}=0.011\right)$ and relationships with adults $\left(F(1,4)=7.01, p<0.001, \eta^{2}=\right.$ $0.008)$. Post hoc analyses indicated that Latino/a or Hispanic youth rated change in STEM career interest, career knowledge, identity, and perseverance significantly higher than students from all other demographic groups (all $p$ 's $<0.001$ ). Additionally, Latino/a or Hispanic students rated change in STEM engagement and critical thinking significantly higher than African American/Black and White/Caucasian students.

Program duration There was a main effect of selfreported program duration (i.e., less than 1 week, $n=310$; $1-3$ weeks, $n=272 ; 4-8$ weeks, $n=346$; greater than 8 weeks, $n=670$ ) for all nine outcomes, including all five STEM attitudes-STEM engagement $(F(1,3)=51.31$, $\left.p<0.001, \eta_{P}^{2}=0.088\right)$, STEM career interest $(F(1,3)=$ 56.51, $\left.p<0.001, \eta_{P}^{2}=0.096\right)$, STEM career knowledge $\left(F(1,3)=71.73, p<0.001, \eta_{P}^{2}=0.119\right)$, STEM activity participation $\left(F(1,3)=49.61, p<0.001, \eta_{P}^{2}=0.085\right)$, and STEM identity $\left(F(1,3)=57.71, p<0.001, \eta^{2}=0.098\right)-$ and all four SEL/twenty-first-century skills-critical thinking $\left(F(1,3)=29.66, p<0.001, \eta_{P}^{2}=0.053\right)$, perseverance $\left(F(1,3)=35.33, p<0.001, \eta_{P}^{2}=0.062\right)$, relationships with adults $\left(F(1,3)=33.90, p<0.001, \eta_{P}^{2}=0.06\right)$, and relationships with peers $(F(1,3)=27.58, p<0.001$, $\eta_{P}^{2}=0.049$ ) (see Fig. 1). Students participating in STEM activities for four or more weeks rated change in all outcomes significantly higher than students participating for 3 weeks or less. Students participating for 1-3 weeks rated change in all outcomes significantly higher than students participating for less than 1 week, but there were no differences between students participating for 4-8 weeks and 8 weeks or more. Program duration contributed to approximately $8 \%$ of the known variance in retrospective posttest scores across all student outcomes, with the largest effects found among students participating for 4-8 weeks and 8 weeks or more.

State There was a main effect of state for all nine scales, including STEM engagement $(F(1,10)=6.21, p<0.001)$, career knowledge $(F(1,10)=12.1, p<0.001)$, career interest $(F(1,10)=6.85, p<0.001)$, activity participation $(F(1,10)=$ $4.48, p<0.001)$, identity $(F(1,10)=7.94, p<0.001)$, critical thinking $(F(1,10)=4.17, p<0.001)$, perseverance $(F(1,10)=$ $4.07, p<0.001)$, relationships with adults $(F(1,10)=6.25$, $p<0.001)$, and relationships with peers $(F(1,10)=3.54$, 


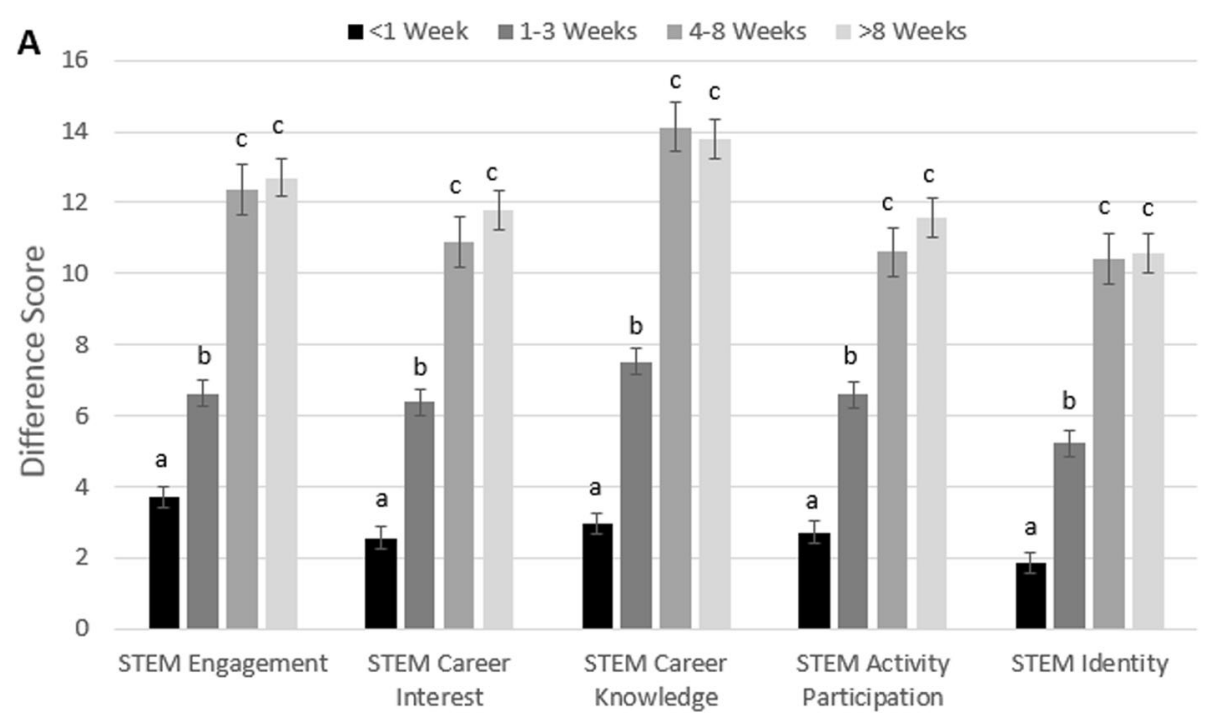

B $16 \quad$ a Week $\square 1-3$ Weeks $\square 4-8$ Weeks $\square>8$ Weeks

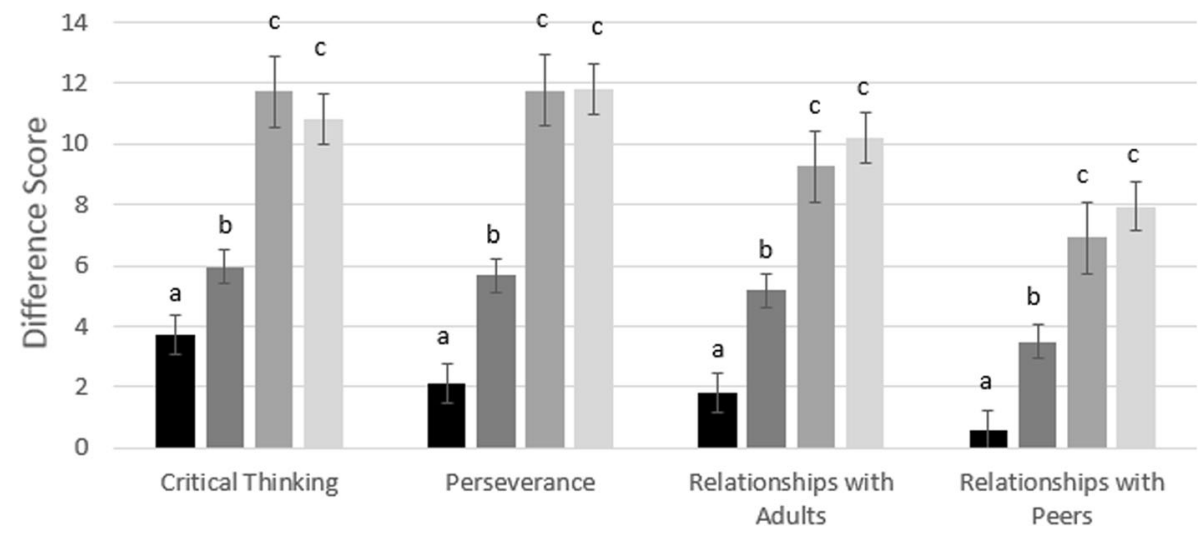

Fig. 1 Mean $( \pm S D)$ retrospective pretest-posttest difference scores for youth self-reported a STEM attitudes and $\mathbf{b}$ SEL/twenty-first-century skills by STEM program duration (using the CIS-S). Means with different letters within each scale are significantly different $(p<0.05)$

$p<0.001$ ) (see Table 4 for between-state post hoc results and effect sizes, all $p$ 's $<0.001)$. Effect size testing indicated that state characteristics contributed to $2 \%$ of the variance in retrospective posttest scores.

\section{Program quality ratings}

\section{Overall program quality}

National strengths and challenges Based on observed levels of STEM program quality across 11 state networks, afterschool programs exhibited more strengths than challenges (see Fig. 2). There were statistically significant differences in quality ratings, on average, between the 12 dimensions assessed $\left(\chi^{2}(11)=938.60, p<0.001\right)$. Specifically, afterschool programs most frequently demonstrated reasonable to compelling evidence of quality (i.e., a minimum rating of 3.0 per dimension) for the three dimensions within the FLE domain (inclusive of the organization, materials, and space utilization dimensions) and the relationships dimension within the YDSTEM domain. Dimensions that proved to be more challenging for programs (based on the percentage of ratings below 3.0), include the three dimensions within the STEMKP domain (STEM content learning, inquiry, reflection) and two dimensions with the YDSTEM domain (youth voice and relevance).

State comparisons There was a main effect of state found for two dimensions of STEM program quality: STEM content learning $\left(\chi^{2}(10)=37.75, p<0.001\right)$-where State 6 exhibited higher quality than States $1,2,4,9$, and 11-and youth voice $\left(\chi^{2}(10)=28.80, p=0.001\right)$-where States 7,8 , and 11 exhibited higher quality than State 4 . These analyses are exploratory, given there were 11 to 28 observations per state, and designed to generate hypotheses. 


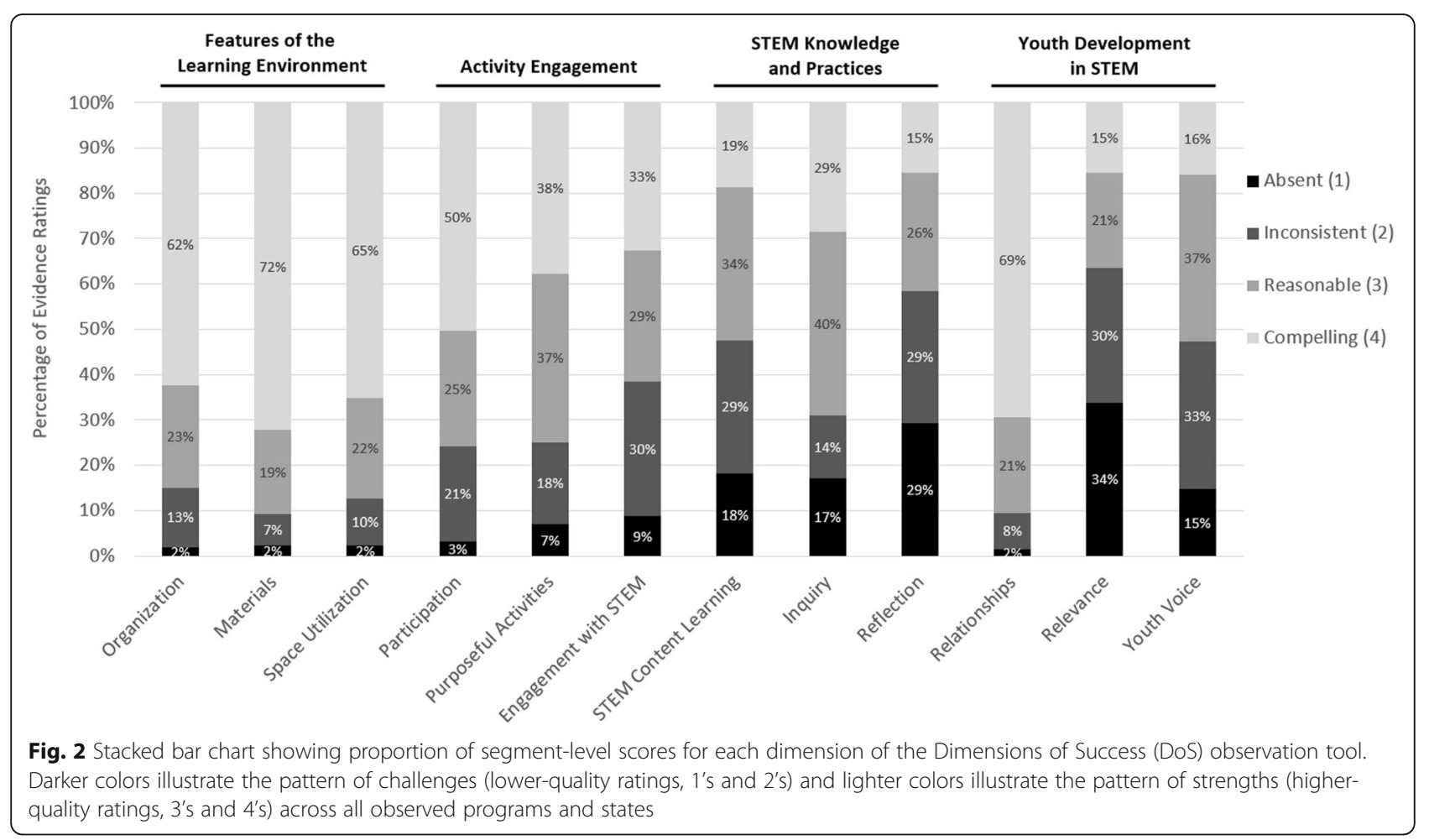

Benchmarking Overall, results showed that more than $82 \%$ of youth participated in afterschool programming that was determined to have overall average or higher levels of STEM program quality. Higher-quality programs received an average rating of $3.67 \pm 0.13$ across the 12 dimensions, meaning the midpoint between reasonable to compelling levels of evidence (Table 5). Average quality programs received an average rating $2.99 \pm 0.26$, closely approximating reasonable evidence of quality. However, there was significant variation in the ratings that equated to average and lower program quality by domain and by dimension (Table 5 ). As shown in Fig. 2 and Table 5, programs more easily met the minimum standard of quality set by DoS (i.e., reasonable evidence, which equates to an average rating of 3.0 per dimension) for the FLE and ActEng domains and their associated dimensions. To be considered a higherquality program in for FLE, a near perfect average score of 4.0 (out of 4.0) was required. However, it was more challenging for afterschool programs (both in this study sample and nationally) to meet the same standard for STEMKP and YDSTEM domains. For instance, average quality for FLE equated to an average dimension rating of $3.55 \pm .55$, about a half point difference above the 3.0 threshold. Conversely, average quality for STEMKP equated to an average dimension score of $2.57 \pm .95$, about a half point difference below the 3.0 threshold, indicating a need for more support in these STEMKP both locally and nationally.
Table 5 Mean ( \pm SD) DoS ratings for STEM-focused afterschool programs that equated to lower, average, or higher levels of STEM program quality by domain and by dimension

\begin{tabular}{|c|c|c|c|}
\hline Dos domain & $\begin{array}{l}\text { Lower } \\
\text { quality }\end{array}$ & $\begin{array}{l}\text { Average } \\
\text { quality }\end{array}$ & $\begin{array}{l}\text { Higher } \\
\text { quality }\end{array}$ \\
\hline Overall STEM program quality & $2.17 \pm 0.53$ & $2.99 \pm 0.26$ & $3.67 \pm 0.13$ \\
\hline $\begin{array}{l}\text { Features of the Learning } \\
\text { Environment }\end{array}$ & $2.68 \pm 0.33$ & $3.54 \pm 0.25$ & $4.00 \pm 0.03$ \\
\hline Organization & $2.54 \pm 0.64$ & $3.41 \pm 0.58$ & $4.00 \pm 0.01$ \\
\hline Materials & $3.00 \pm 0.58$ & $3.67 \pm 0.48$ & $4.00 \pm 0.07$ \\
\hline Space utilization & $2.51 \pm 0.64$ & $3.55 \pm .051$ & $4.00 \pm 0.02$ \\
\hline Activity Engagement & $2.00 \pm 0.07$ & $3.09 \pm 0.36$ & $3.95 \pm 0.07$ \\
\hline Participation & $2.07 \pm 0.40$ & $3.25 \pm 0.67$ & $3.92 \pm 0.18$ \\
\hline Purposeful activities & $2.13 \pm 0.72$ & $3.15 \pm 0.55$ & $4.00 \pm 0.03$ \\
\hline STEM engagement & $1.79 \pm 0.51$ & $2.89 \pm 0.69$ & $3.95 \pm 0.15$ \\
\hline STEM Knowledge and Practices & $1.48 \pm 0.36$ & $2.58 \pm 0.41$ & $3.51 \pm 0.24$ \\
\hline STEM content learning & $1.49 \pm 0.64$ & $2.61 \pm 0.78$ & $3.57 \pm 0.40$ \\
\hline Inquiry & $1.71 \pm .052$ & $2.94 \pm 0.67$ & $3.56 \pm 0.51$ \\
\hline Reflection & $1.26 \pm 0.37$ & $2.20 \pm 0.70$ & $3.51 \pm 0.46$ \\
\hline Youth Development in STEM & $1.83 \pm 0.31$ & $2.87 \pm 0.35$ & $3.73 \pm 0.15$ \\
\hline Relationships & $2.35 \pm 0.80$ & $3.71 \pm 0.49$ & $4.00 \pm 0.01$ \\
\hline Relevance & $1.35 \pm 0.52$ & $2.25 \pm 0.85$ & $3.54 \pm 0.46$ \\
\hline Youth voice & $1.78 \pm 0.58$ & $2.66 \pm 0.62$ & $3.66 \pm 0.39$ \\
\hline
\end{tabular}

Note: DoS dimensions are rated on a 4-point scale from 1 (evidence absent) to 4 (compelling evidence), where the goal is to achieve an average rating of 3 (reasonable evidence) or higher. Sample size for overall STEM program quality was as follows: lower, $n=279$ students across 28 programs; average, $n=972$ students across 91 programs; higher, $n=348$ students across 27 programs 
Relationships within and across measures Linking student STEM attitudes and twenty-first-century skills There were significant, moderate to strong, positive correlations between average ratings for all five STEMrelated scales and the four SEL/twenty-first-century skills (all $p$ 's $<0.001$, see Table 6 ). All $r$ values between all STEM-related outcomes and SEL/twenty-first-century skills (based upon retrospective posttest scores) ranged between 0.319 and 0.759 , which represents a shared variance between the variables of $10.1 \%$ to $57.6 \%$. Generally, SEL/twenty-first-century skills showed the highest correlations with STEM engagement and STEM career interest relative to other STEM-related scales, albeit the strength of correlations for all tended to be moderate to strong. The strongest correlation found between STEM outcomes and SEL/twenty-first-century skills was between change in STEM engagement and change in critical thinking, $(r(1597)=0.759, p<0.001$, $d=2.33$ ) (see Table 6).

\section{Linking STEM program quality and youth outcomes}

Students attending programs observed to have higher levels of program quality reported significantly greater gains in all STEM-related attitudes, with the exception of STEM activity participation, and all SEL/twenty-first-century skills than students attending programs observed to have lower levels of program quality (see Table 7 for statistics, all $p$ 's $<0.005)$. As shown in Table 7 , the largest effect sizes for overall program quality were found for STEM identity, career knowledge, relationships with adults, and perseverance, respectively, which were moderate in size according to Hattie (2012). We performed post hoc analyses for each of the four DoS domains separately to examine whether the relationships between quality and youth outcomes differ by domain. We found that FLE had the weakest effect on youth outcomes-with fewer statistically significant differences found for the effect of this quality domain on youth outcomes-and STEMKP had the strongest effect on youth outcomes-with more statistically significant differences found for the effect of this quality domain on youth outcomes (Table 7). Program quality based on STEMKP alone also produced larger effect sizes than the other DoS domains. Notably, each of the four domains was necessary, but not sufficient, to detect statistically significant effects on youth outcomes. In other words, all four DoS domains (and all 12 dimensions) combined into one composite score resulted in the most robust differences across youth outcomes than any of the domains alone.

\section{Discussion}

This study of an afterschool and STEM system-building intervention served as a proof point of the capacity of the US afterschool field to implement an evidence-based approach on a national scale to inform STEM research and practice. Using a common set of assessments developed collaboratively by researchers and practitioners, this study has the potential to advance the STEM education field's current understanding of STEM program quality and outcomes in afterschool settings. The study contributed actionable results on local, state, and national levels to influence policy and improve practice. State network leaders were provided with detailed reports with state- and program-level results within 3 months of this study's conclusion. They have used their program quality and youth outcome data to identify key strengths and areas for improvement, to successfully obtain funding, and to advocate for state and national policy reform to promote best practices for STEM education and strengthen workforce development. The following sections expand upon key findings, which add to the published literature.

Table 6 Correlations between STEM attitudes and SEL/twenty-first-century skills reported on CIS-S

\begin{tabular}{|c|c|c|c|c|c|c|c|c|c|}
\hline Variable & 1 & 2 & 3 & 4 & 5 & 6 & 7 & 8 & 9 \\
\hline \multicolumn{10}{|l|}{ STEM attitudes } \\
\hline 1. STEM engagement & - & & & & & & & & \\
\hline 2. STEM career interest & .851 & - & & & & & & & \\
\hline 3. STEM career knowledge & .773 & .740 & - & & & & & & \\
\hline 4. STEM activity participation & .720 & .632 & .783 & - & & & & & \\
\hline 5. STEM identity & .871 & .834 & .844 & .787 & - & & & & \\
\hline \multicolumn{10}{|l|}{ SEL/twenty-first-century skills } \\
\hline 6. Critical thinking & .759 & .740 & .559 & .430 & .613 & - & & & \\
\hline 7. Perseverance & .673 & .697 & .562 & .423 & .593 & .858 & - & & \\
\hline 8. Relationships with adults & .631 & .620 & .526 & .481 & .542 & .764 & .783 & - & \\
\hline 9. Relationships with peers & .450 & .539 & .398 & .319 & .373 & .649 & .645 & .715 & - \\
\hline
\end{tabular}

Note: Correlations between all scales are positive and significant at $p<0.001$ (and for all scales, $n=1599$, df $=1597$ ). Coefficients printed in italics have large effect sizes $(r>0.5)$. Correlations are based on CIS-S retrospective-post scores, which represent average ratings of students' thoughts and feelings "at this time," meaning the end of programming. SEL social-emotional learning 


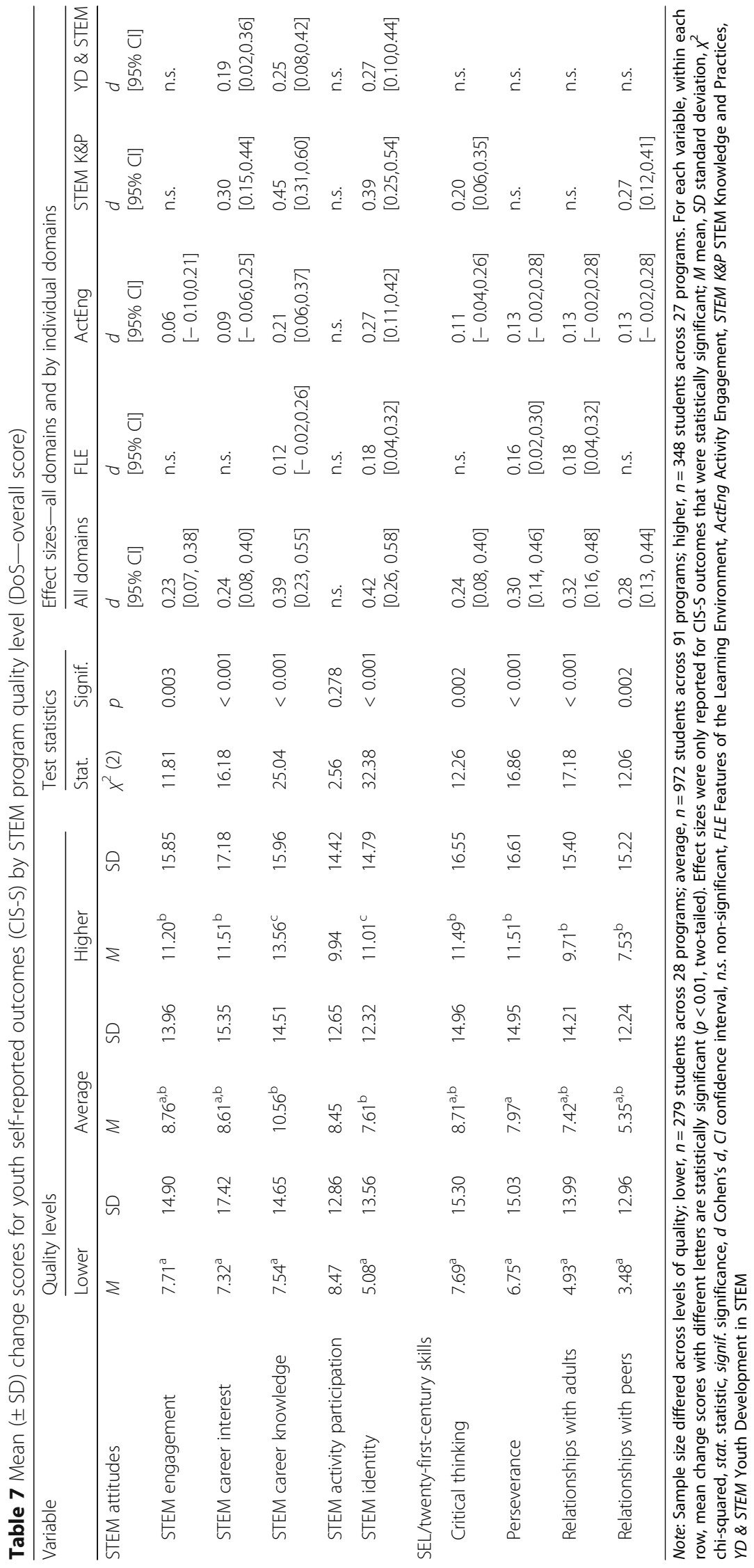




\section{National trends in youth outcomes}

Overall, our findings showed that all states exhibited significant, positive youth outcomes, with approximately $65-85 \%$ of students reporting significant gains in STEM attitudes and SEL/twenty-first-century skills across the 11 state afterschool networks. Five states showed large effects for two or more youth outcomes, and all states showed medium effects for one or more outcomes. We made this determination using the interpretation guidelines provided by Hattie (2012), where an intervention has a medium effect when the $d$ value is between 0.3 and 0.6 and a large effect when the $d$ value is 0.6 and greater. State effects sizes ranged from small to large $(d$ values ranging from .15 to .68 depending on outcome and state), which is expected given the diversity of states and programs and other uncontrolled factors, such as state networks being in different phases of systembuilding implementation or using different strategies for supporting and training programs.

There is anecdotal evidence from state leaders and technical assistance consultants that suggests the effect size patterns are consistent with our understanding of how states differed in their experience level, resources, focus, and implementation of the system-building intervention. However, further study is required to weigh the impact of specific system-building strategies on program quality dimensions and youth attitudes. Results may also be influenced by the demographic makeup of the study sample and other unobserved factors in youth, such as individual interests, abilities, education, opportunities, and background.

\section{Gender and youth outcomes}

Gender did not play a significant role in student STEMrelated attitudes in the present study, which contrasts with many published findings showing that boys have significantly more positive STEM-related attitudes than girls (Desy, Peterson, \& Brockman, 2011; Weinburgh, 1995). A possible reason for this could be that youth who participate in afterschool STEM programs are already a self-selected group based off their current interest in STEM (Vallett, Lamb, \& Annetta, 2018). However, this finding is consistent with studies finding that men and women perceive similar educational benefits when participating in hands-on STEM-related experiences, such as undergraduate research experiences (Harsh, Maltese, \& Tai, 2012; Lopatto, 2004; Russell, Hancock, \& McCullough, 2007). Prior research has also found that participation in informal research experiences is more often a deciding factor to pursue an advance STEM degree for women than it is for men (Harsh et al., 2012), suggesting that afterschool may be another setting that narrows the gender gap in STEM achievement and career outcomes.
There was a small but significant effect of gender on students' perceived quality of relationships with adults and peers. Compared to male students, female students reported higher-quality relationships with peers and adults at both the beginning and end of programming. This finding is consistent with literature describing gender differences in perceived quality of relationships (Fabes et al., 2014). However, more research is needed to understand how gender differences in perceptions may influence afterschool program dynamics or future academic and career success, especially in STEM fields.

\section{Grade level and youth outcomes}

An examination of student outcomes by grade level indicated that there were no differences in STEM attitudes and SEL/twenty-first-century skills based on year in school between grades 4 to 12 . Again, it is possible that the lack of grade differences is related to the selfselected nature of most afterschool programs; youth in the present study may have developed a stronger interest and identity in STEM than other youth who self-selected into other types of programming (Vallett et al., 2018). However, evidence in the literature is mixed; there are examples of studies conducted in school settings that report a decline in STEM interest and motivation from elementary school to high school (Potvin \& Hasni, 2014; VanLeuvan, 2004), and there are also examples of studies conducted in afterschool program settings that suggest that consistent participation in STEM activities buffer against a decline in STEM interest and motivation over time (Chittum et al., 2017). Further work is needed to examine attitudes longitudinally and between different learning settings (e.g., informal and formal learning settings) to understand the influence of afterschool on various STEM attitudes.

\section{Race and ethnicity and youth outcomes}

The finding that Latino/a or Hispanic youth reported the greatest gains in STEM attitudes and SEL/twentyfirst-century skills is very encouraging. While Latino/as are significantly underrepresented in STEM, the share of science and engineering bachelor's degrees awarded to this demographic group has increased significantly over the past 20 years, currently accounting for between 10.4 and $13.5 \%$ of engineering and science bachelor's degrees, respectively (National Center for Science and Engineering Statistics, National Science Foundation, 2019). The present findings are consistent with recent literature. For example, Hsieh, Liu, and Simpkins (2019) found that Latino/a high school students who perceived more support in science had higher science motivational beliefs than those who perceived less support. Additionally, Riggs, Bohnert, Guzman, and Davidson (2010) found that rural Latino/a grade-school youth who regularly 
attended community-based afterschool programing had developed stronger ethnic identities as well as better concentration and emotion regulation skills than Latino/ a youth who did not regularly attend. However, there is a need for more in-depth studies on how afterschool STEM specifically supports specific racial and ethnic groups that are often underrepresented in the literature and in the STEM fields.

\section{National Trends in STEM program quality and participation} Observations of STEM program quality indicated that programs excel in creating positive and supportive informal learning environments with well-prepared activities and fun and engaging materials. However, about 30$50 \%$ of programs need more support to help youth understand STEM concepts, make connections, and participate in inquiry practices. In addition to the quality of STEM activities, the length of time that youth engage in programming was an important factor that significantly influenced outcomes. The present data indicated that a minimum of $1 \mathrm{~h}$ of STEM per week for 4 weeks or longer positively and significantly influenced students' STEMrelated attitudes and SEL/twenty-first-century skills. Taken together, these findings underscore the importance of both quality and duration in the design of STEM programming (Fredricks et al., 2017).

\section{Linking STEM program quality and youth outcomes}

Importantly, this study provides evidence to substantiate the linkage between program quality and student outcomes and also underscores the importance of focusing on quality improvement to enhance student learning experiences. Specifically, students participating in higherquality programming, relative to peers participating in lower-quality programs, reported feeling more positive about STEM because of their afterschool experience-including being more excited about STEM and innovation, more interested in pursuing STEM careers, and more knowledgeable about what careers exist and the steps to obtain them.

The STEM Knowledge and Practices domain had the strongest effect on STEM attitudes and SEL/twenty-firstcentury skills reported by students. In other words, while a lower-quality rating in any of the four domains was associated with less positive outcomes among students, this effect was much more substantial for programs with lower-quality ratings in the STEM Knowledge and Practices domain. However, this DoS domain has proven to be the most challenging for afterschool STEM programs to master, which underscores the need for further professional development in STEM content learning, inquiry, and reflection (Shah et al., 2018). The present findings suggest that helping students grapple with STEM concepts, practices, and knowledge in a meaningful way can significantly improve important outcomes including STEM identity, career interest and motivation, perseverance, and quality of relationships.

\section{Connections between STEM attitudes and SEL/twenty- first-century skills}

One other notable finding was the convergence between STEM attitudes and SEL/twenty-first-century skills, underscoring how the integration of a youth development focus may enhance STEM learning and engagement, and vice versa. There is growing evidence and consensus that there is a natural integration between STEM and SEL/twentyfirst-century skills that can enhance the depth and quality of learning overall (Afterschool Alliance, 2017; Lyon et al., 2012). However, few studies in school and afterschool/ OST settings have explicitly and intentionally studied the potential synergy between SEL/twenty-first-century skills and STEM learning, underscoring a promising avenue for future afterschool STEM research to map the landscape and build the evidential foundation (The Aspen Institute \& Boston Consulting Group, 2018).

\section{Limitations and future directions}

Research studies in the afterschool field are subject to many challenges, such as the many sources of variation that are difficult to measure or control. There are differences in learning settings, programming focus, curriculum usage, implementation capacity and strategy, and membership, to name a few (Halpern, 2006). These challenges make it difficult for the afterschool field to conduct research, provide evidence of effectiveness, and parcel out factors that influence cause and effect. This study is not without its own limitations, which are discussed below along with its strengths and directions for future research.

First, the national scope of the work, albeit a strength in terms of representativeness of the sample, introduces many sources of variability when considering regional, demographic, cultural, political, organizational, strategic, and programmatic differences across the US. While the measurement tools used in the present study were sensitive to individual-, local-, and state-level differences in program quality and outcomes, additional study is needed to understand why differences were found and how the results might differ across learning settings. Future studies are needed to drill deeper into differences by states and programs to identify predictors of the differences in program quality and youth outcomes.

Second, we did not examine actual change in STEMrelated abilities or skills. The field has been very resistant-for good reason-to rely on academic performance measures, especially as many afterschool programs are youth development-based and do not teach directly to academic performance. Afterschool programs engage 
cognitive skills that are not well captured by schoolbased assessments, and unsurprisingly, previous studies examining the effects of afterschool programming on academic achievement using traditional assessments have demonstrated modest effect sizes at best (Halpern, 2006). The present study measured attitudes that may be stronger predictors of future success in STEM than academic achievement scores (e.g. Tai et al., 2006). Still, further study is needed to examine change in abilities using traditional pretest-posttest measurement.

Third, we acknowledge the potential concerns related to the use of a retrospective pretest-posttest design to measure change in students' attitudes and beliefs, including memory-related problems (e.g., memory distortion, selective perception, and poor memory, especially among children and adolescents), social desirability, and impression management and response bias (for review, see Little et al., 2019). Despite these concerns, we determined that the advantages of using a retrospective survey design outweighed the disadvantages in this particular case. One concern was the possibility of biased responses at the pretest, which could occur particularly when the constructs of interest are noncognitive in nature and the goal is to measure change in perceptions over time (Miller \& Hinshaw, 2012; Sprangers \& Hoogstraten, 1989). The frame of reference can also be unclear to the respondent (Nieuwkerk \& Sprangers, 2009), which may lead to what is termed the "response-shift bias" (Howard, 1980). The retrospective pretest-posttest design minimizes or removes these concerns by guiding respondents to focus on themselves at a specific point in time (Drennan \& Hyde, 2008). Lastly, one survey administration with the retrospective method addresses practical concerns held by states and programs, such as levels of attrition in afterschool attendance and amount of resources required, as well as other methodological concerns, such as retest and test reactivity effects (for review, see Little et al., 2018).

Finally, additional work is needed to develop a logic model to assess an "if-then" causal relationship. While the evidence showed that the connection between STEM program quality and youth outcomes is robust, we cannot yet show the theory of change because the strategies and activities within each state are unique. Although all states have common system-building elements, states are in distinct phases of system building implementation, and each approach is tailored to the specific assets and needs of the states and the states' partners. Future work will be needed to better understand and quantify the strategies, resources, and progress of the state networks and programs. Implementation of a gold standard design, namely a randomized controlled trial, to measure impact of afterschool programming on STEM learning is warranted but premature until more research has been done to understand such factors as regional differences in programming (e.g., demographics, socioeconomic factors) and state afterschool network factors (e.g., capacity, resources, strategy, maturity, and approach).

\section{Conclusions and recommendations}

This study adds to the large and growing literature about the positive effects of afterschool STEM on children and youth enrolled in programming (Afterschool Alliance, 2015; Dabney et al., 2012; National Research Council, 2015; Young et al., 2017). While there were many higherquality programs identified, the work to improve afterschool STEM programming is ongoing and there needs to be more research, training, collaboration, and technical assistance to continue this positive trend. Based on several quality indicators and outcomes captured in this work, we make the following recommendations for afterschool and STEM researchers and practitioners.

First, we recommend that states and programs prioritize research and evaluation using a common framework, common language, and common tools. This can become a model in which other large-scale projects in many different educational venues can monitor themselves over time to track successes and challenges in each state, to use the results to improve everyday practice (e.g., decide where and how to invest professional development and coaching efforts, such as in STEM Knowledge and Practices), and to expand advocacy and policy efforts based on evidence. Second, we recommend more intentional and evidencebased methods to integrate STEM and SEL/twenty-firstcentury skills. Afterschool STEM learning experiences provide opportunities to develop SEL/twenty-first-century skills by sparking youth interest in STEM with hands-on activities (to promote active engagement), providing role models (to encourage identity and belonging), allowing youth to make decisions around the steps in an activity (to foster youth voice and assertiveness), and encouraging thoughtful questions and application to everyday life (to practice reflection and relevance). Third, we recommend that the afterschool field work to build capacity and deepen partnerships among researchers and practitioners to create communities of practice around the collection, use, and interpretation of data.

\section{Abbreviations \\ ActEng: Activity engagement; ANOVA: Analysis of variance; CIS-S: Common Instrument Suite-Student; DoS: Dimensions of Success; FLE: Features of the Learning Environment; HSD: Honestly significant difference: \\ OECD: Organisation for Economic Co-operation and Development; PMD: Planned missing data; STEM: Science, technology, engineering, and mathematics; STEMKP: STEM Knowledge and Practices; US: United States; VAS: Visual analog scale; YDSTEM: Youth Development in STEM}

\section{Acknowledgments}

We would like to thank Ron Ottinger of the STEM Next Opportunity Fund, Gwynn Hughes of the Charles Stewart Mott Foundation, and Victoria Wegener of Mainspring Consulting for their continuous support throughout this 
project. We also thank Dr. Ashima Shah and Rebecca Brown at The PEAR Institute: Partnerships in Education and Resilience for leading trainings and aiding quality observations and interpretations using the Dimensions of Success (DoS) observation tool. We thank the network leads of the 11 state afterschool networks, their staff, and all 158 programs, especially their educators, children, and youth. We could not have done this work without everyone's active participation.

\section{Authors' contributions}

All authors contributed extensively to the work presented in this paper and approved the final manuscript. All authors contributed to the study design and methods. GGN developed the student survey and observation tool in partnership with colleagues and practitioners in previous work. PJA and EF coordinated the study with the state networks and afterschool programs. $\mathrm{TDL}, \mathrm{RC}, \mathrm{BKG}$, and LW managed the collection and analysis of survey data and the implementation of the planned missing data design for student surveys. GGN managed the team that trained and certified DoS program quality observers, and PJA managed the collection and analysis of DoS observation data. PJA and GGN wrote the manuscript with significant input from all other authors. All authors discussed the results and implications and commented on the manuscript at all stages.

\section{Funding}

Support for this work was provided by grants from the Charles Stewart Mott Foundation and the STEM Next Opportunity Fund (Noam, PI).

\section{Availability of data and materials}

The datasets used and analyzed during the current study are available from the corresponding author on reasonable request.

\section{Competing interests}

The authors declare that they have no competing interest.

\section{Author details}

'The PEAR Institute, McLean Hospital and Harvard Medical School, Belmont, MA, USA. ${ }^{2}$ Institute for Measurement, Methodology, Analysis, \& Policy, Texas Tech University, Lubbock, TX, USA. ${ }^{3}$ Optentia Research Focus Area, North-West University, Vanderbij|park, South Africa.

\section{Received: 26 February 2019 Accepted: 27 September 2019}

Published online: 12 November 2019

\section{References}

Afterschool Alliance. (2014). America after 3pm: Afterschool programs in demand Retrieved from Afterschool Alliance website: http://wnw.afterschoolalliance.org/AA3PM/

Afterschool Alliance. (2015). Full STEM ahead: Afterschool programs step up as key partners in STEM education Retrieved from Afterschool Alliance website: http://www.afterschoolalliance.org/AA3PM/STEM.pdf.

Afterschool Alliance. (2017). Building workforce skills in afterschool (issue brief no. 70) Retrieved from afterschool Alliance website: http://afterschoolalliance.org/ documents/issue_briefs/issue_workforce_readiness_70.pdf.

Aschbacher, P. R., Ing, M., \& Tsai, S. M. (2014). Is science me? Exploring middle school students' STE-M career aspirations. Journal of Science Education and Technology, 23(6), 735-743. https://doi.org/10.1007/s10956-014-9504-x.

Barton, A. C., \& Tan, E. (2010). We be burnin'! Agency, identity, and science learning. Journal of the Learning Sciences, 19(2), 187-229. https://doi.org/10. 1080/10508400903530044

Bell, C., Gitomer, D., Mccaffrey, D., Hamre, B., C. Pianta, R., \& Qi, Y. (2012). An argument approach to observation protocol validity. Educational Assessment, 17, 62-87. https://doi.org/10.1080/10627197.2012.715014.

Bell, C., Qi, Y., Croft, A. J., Leusner, D. W., McCaffrey, D., Gitomer, D. H., \& Pianta, R. C. (2014). Improving observational score quality: challenges in observer thinking. In T. J. Kane, K. A. Kerr, \& R. C. Pianta (Eds.), Designing teacher evaluation systems: New guidance from the measures of effective teaching project (pp. 50-97). San Francisco: Jossey-Bass.

Bell, P., Lewenstein, B., Shouse, A. W., \& Feder, M. A. (Eds.). (2009). Learning science in informal environments: people, places, and pursuits. National Research Council, 4(1), 113-124. https://doi.org/10.1179/msi. 2009.4.1.113.

Chittum, J. R., Jones, B. D., Akalin, S., \& Schram, A. B. (2017). The effects of an afterschool STEM program on students' motivation and engagement.
International Journal of STEM Education, 4(1). https://doi.org/10.1186/s40594 017-0065-4.

Coburn, C. E., \& Penuel, W. R. (2016). Research-practice partnerships in education: outcomes, dynamics, and open questions. Educational Researcher, 45(1), 4854. https://doi.org/10.3102/0013189X16631750.

Cribbs, J. D., Hazari, Z., Sonnert, G., \& Sadler, P. M. (2015). Establishing an explanatory model for mathematics identity. Child Development, 86(4), 10481062. https://doi.org/10.1111/cdev.12363.

Dabney, K. P., Tai, R. H., Almarode, J. T., Miller-Friedmann, J. L., Sonnert, G., Sadler, P. M., \& Hazari, Z. (2012). Out-of-school time science activities and their association with career interest in STEM. International Journal of Science Education, Part B, 2(1), 63-79. https://doi.org/10.1080/21548455.2011.629455.

Desy, E. A., Peterson, S. A., \& Brockman, V. (2011). Gender differences in sciencerelated attitudes and interests among middle school and high school students. Science Educator, 20(2), 23-30.

Drennan, J., \& Hyde, A. (2008). Controlling response shift bias: The use of the retrospective pre-test design in the evaluation of a master's programme. Assessment \& Evaluation in Higher Education, 33(6), 699-709. https://doi.org/ 10.1080/02602930701773026.

Fabes, R. A., Hayford, S., Pahlke, E., Santos, C., Zosuls, K., Martin, C. L., \& Hanish, L. D. (2014). Peer influences on gender differences in educational aspiration and attainment. In I. Schoon \& J. S. Eccles (Eds.), Gender differences in aspirations and attainment: A life course perspective (pp. 29-52). Cambridge: Cambridge University Press.

Fredricks, J. A., Naftzger, N., Smith, C., \& Riley, A. (2017). Measuring youth participation, program quality, and social and emotional skills in after-school programs. In N. L. Deutsch (Ed.), After-school programs to promote positive youth development (Vol. 1, pp. 23-43). https://doi.org/10.1007/978-3-319-59132-2_3.

Friedman, A. J. (2008). Report from a National Science Foundation workshop (p. 114). Washington, D.C.: National Science Foundation.

Graham, M. J., Frederick, J., Byars-Winston, A., Hunter, A.-B., \& Handelsman, J. (2013). Increasing persistence of college students in STEM. Science, 341(6153), 1455-1456. https://doi.org/10.1126/science.1240487.

Halpern, R. (2006). Confronting "the big lie": The need to reframe expectations of afterschool programs Retrieved from https://www.erikson.edu/research/confrontingthe-big-lie-the-need-to-reframe-expectations-of-after-school-programs/.

Harsh, J. A., Maltese, A. V., \& Tai, R. H. (2012). A perspective of gender differences in chemistry and physics undergraduate research experiences. Journal of Chemical Education, 89(11), 1364-1370. https://doi.org/10.1021/ed200581m.

Hattie, J. (2012). Visible learning for teachers: Maximizing impact on learning. https://doi.org/10.4324/9780203181522.

Howard, G. S. (1980). Response-shift bias: a problem in evaluating interventions with pre/post self-reports. Evaluation Review, 4, 93-106. https://doi.org/10. 1177/0193841X8000400105

Hsieh, T., Liu, Y., \& Simpkins, S. D. (2019). Changes in United States Latino/a high school students' science motivational beliefs: within group differences across science subjects, gender, immigrant status, and perceived support. Frontiers in Psychology, 10, 380. https://doi.org/10.3389/fpsyg.2019.00380.

Kidd, G., \& Naylor, F. (1991). The predictive power of measured interests in tertiary course choice: the case of science. Australian Journal of Education, 35(3), $261-$ 272. https://doi.org/10.1177/000494419103500304.

Krishnamurthi, A., Ottinger, R., \& Topol, T. (2013). STEM learning in afterschool and summer programming: an essential strategy for STEM education reform. In T. K. Peterson (Ed.), Expanding minds and opportunities: Leveraging the power of afterschool and summer learning for students Retrieved from http://www.expandinglearning.org/ expandingminds/article/stem-learning-afterschool-and-summerprogramming-essential-strategy-stem.

Little, T. D., Chang, R., Gorrall, B. K., Waggenspack, L., Fukuda, E., Allen, P. J., \& Noam, G. G. (2019). The retrospective pretest-posttest design redux: On its validity as an alternative to traditional pretest-posttest measurement. International Journal of Behavioral Development. https://doi.org/10.1177/ 0165025419877973

Little, T. D., Jorgensen, T. D., Lang, K. M., \& Moore, E. W. G. (2014). On the joys of missing data. Journal of Pediatric Psychology, 39(2), 151-162. https://doi.org/ 10.1093/jpepsy/jst048.

Lopatto, D. (2004). Survey of undergraduate research experiences (SURE): first findings. Cell Biology Education, 3(4), 270-277. https://doi.org/10. $1187 /$ cbe.04-07-0045.

Lyon, G. H., Jafri, J., \& St. Louis, K. (2012). Beyond the pipeline: STEM pathways for youth development. Afterschool Matters, 16, 48-57. 
Maltese, A. V., \& Tai, R. H. (2010). Eyeballs in the fridge: sources of early interest in science. International Journal of Science Education, 32(5), 669-685. https://doi. org/10.1080/09500690902792385.

Maltese, A. V., \& Tai, R. H. (2011). Pipeline persistence: examining the association of educational experiences with earned degrees in STEM among U.S. students. Science Education, 95(5), 877-907. https://doi.org/10.1002/sce.20441.

Malti, T., Zuffianò, A., \& Noam, G. G. (2017). Knowing every child's social-emotional development: toward the use of developmental tools in psychological intervention. Prevention Science, 1-12. https://doi.org/10.1007/s11121-017-0794-0.

Martinez, A., Linkow, T., Velez, M., \& DeLisi, J. (2014). Evaluation study of summer of innovation stand-alone program model FY 2013: Outcomes report for National Aeronautics and Space Administration (NASA). Waltham, MA: Abt Associations.

Merolla, D. M., \& Serpe, R. T. (2013). STEM enrichment programs and graduate school matriculation: the role of science identity salience. Social Psychology of Education, 16(4), 575-597. https://doi.org/10.1007/s11218-013-9233-7.

Miller, M., \& Hinshaw, R. E. (2012). The retrospective pretest as a gauge of change. Journal of Instructional Psychology, 39, 251-258.

Moakler, M. W., \& Kim, M. M. (2014). College major choice in STEM: Revisiting confidence and demographic factors. The Career Development Quarterly, 62(2), 128-142. https://doi.org/10.1002/j.2161-0045.2014.00075.x.

Morgan, P. L., Farkas, G., Hillemeier, M. M., \& Maczuga, S. (2016). Science achievement gaps begin very early, persist, and are largely explained by modifiable factors. Educational Researcher, 45(1), 18-35. https://doi.org/10. 3102/0013189X16633182

Mott Foundation and STEM Next. (2018). STEM in afterschool system-building toolkit Retrieved August 8, 2018, from http://expandingstemlearning.org/.

Naftzger, N., Sniegowski, S., Smith, C., \& Riley, A. (2018). Exploring the relationship between afterschool program quality and youth development outcomes: Findings from the Washington quality to youth outcomes study (pp. 1-47) Retrieved from American Institutes for Research website: https:/raikesfoundation.org/sites/ default/files/washington-quality-youth-outcomes-study.pdf.

National Center for Science and Engineering Statistics, National Science Foundation. (2019). Women, minorities, and persons with disabilities in science and engineering: 2019, No. special report NSF 19-304 Retrieved from National Science Foundation website: https://ncses.nsf.gov/pubs/nsf19304/digest.

National Research Council. (2002). Community programs to promote youth development. https://doi.org/10.17226/10022.

National Research Council. (2009). Learning science in informal environments: People, places, and pursuits Retrieved from https://www.nap.edu/ catalog/12190/learning-science-in-informal-environments-people-placesand-pursuits.

National Research Council. (2015). Identifying and supporting productive STEM programs in out-of-school settings. https://doi.org/10.17226/21740.

Nieuwkerk, P. T., \& Sprangers, M. A. G. (2009). Each measure of patient-reported change provides useful information and is susceptible to bias: the need to combine methods to assess their relative validity. Arthritis and Rheumatism, 61(12), 1623-1625. https://doi.org/10.1002/art.25030.

Noam, G. G., Malti, T., \& Guhn, M. (2012). From clinical-developmental theory to assessment: the holistic student assessment tool. International Journal of Conflict and Violence, 6(2), 201-213. https://doi.org/10.4119/UNIBI/ijcv.276.

Noam, G. G., \& Shah, A. (2014). Informal science and youth development: creating convergence in out-of-school time. Teachers College Record, 116(13), 199-218.

Noam, G. G., \& Shah, A. M. (2013). Game-changers and the assessment predicament in afterschool science Retrieved from the PEAR institute: Partnerships in education and resilience website: http://www.pearweb.org/research/pdfs/ Noam\%26Shah_Science_Assessment_Report.pdf.

Noam, G. G., Allen, P. J., Shah, A. M., \& Triggs, B. B. (2017). Innovative use of data as game changer for afterschool: the example of STEM. In H. J. Malone \& T. Donahue (Eds.), Current issues in out-of-school time. The growing out-of-school time field: Past, present, and future. Charlotte: Information Age Publishing.

OECD. (2007). PISA 2006: Science competencies for tomorrow's world (Vol. 1) Retrieved from https://www.oecd-ilibrary.org/education/pisa-2006_9789264040014-en.

OECD. (2014). PISA 2012 results: What students know and can do (revised edition) Retrieved from http://www.oecd-ilibrary.org/education/pisa-2012-resultswhat-students-know-and-can-do-volume-i-revised-edition-february-2014_ 9789264208780-en.

OECD. (2015). Key findings from PISA 2015 for the United States Retrieved from https://www.oecd.org/pisa/PISA-2015-United-States.pdf.

Oh, Y., Osgood, D. W., \& Smith, E. P. (2015). Measuring afterschool program quality using setting-level observational approaches. The Journal of Early Adolescence, 35(5-6), 681-713. https://doi.org/10.1177/0272431614561261.
Osborne, J., Simon, S., \& Collins, S. (2003). Attitudes towards science: A review of the literature and its implications. International Journal of Science Education, 25(9), 1049-1079. https://doi.org/10.1080/ 0950069032000032199

Pellegrino, J. W. E., \& Hilton, M. L. E. (2012). Education for life and work: Developing transferable knowledge and skills in the 21st century. https://doi.org/10.17226/13398.

Potvin, P., \& Hasni, A. (2014). Analysis of the decline in interest towards school science and technology from grades 5 through 11. Journal of Science Education and Technology, 23(6), 784-802. https://doi.org/10.1007/s10956014-9512-x.

Potvin, P., \& Hasni, A. (2014). Interest, motivation and attitude towards science and technology at K-12 levels: A systematic review of 12 years of educational research.. Studies in Science Education ,50(1), 85-129. https://doi.org/10.1080/ 03057267.2014.881626.

Price, L. R. (2018a). Common instrument suite - retrospective sample. In Methodology, measurement, and statistical analysis (MMSA) (pp. 1-44) Technical report). San Marcos: Texas State University.

Price, L. R. (2018b). Holistic student assessment - retrospective sample [Technical report. In Methodology, measurement, and statistical analysis (MMSA). San Marcos: Texas State University.

Riggs, N. R., Bohnert, A. M., Guzman, M. D., \& Davidson, D. (2010). Examining the potential of community-based after-school programs for Latino youth. American Journal of Community Psychology, 45(3-4), 417-429. https://doi.org/ 10.1007/s10464-010-9313-1.

Robnett, R. D., \& Leaper, C. (2013). Friendship groups, personal motivation, and gender in relation to high school students' STEM career interest. Journal of Research on Adolescence, 23(4), 652-664. https://doi.org/10.1111/jora.12013.

Rothwell, J. (2014). Job vacancies and STEM skills. In Metropolitan Policy Program at Brookings (p. 44).

Russell, S. H., Hancock, M. P., \& McCullough, J. (2007). Benefits of undergraduate research experiences. Science, 316(5824), 548-549. https://doi.org/10.1126/ science.1140384

Sahin, A., Ayar, M. C., \& Adiguzel, T. (2013). STEM related after-school program activities and associated outcomes on student learning. Educational Sciences: Theory \& Practice, 14(1). https://doi.org/10.12738/estp.2014.1.1876.

Shah, A. M., Wylie, C., Gitomer, D., \& Noam, G. G. (2018). Improving STEM program quality in out-of-school-time: tool development and validation. Science Education, 102(2). https://doi.org/10.1002/sce.21327.

Sneider, C., \& Noam, G. G. (2019). The common instrument suite: a means for assessing student attitudes in STEM classrooms and out-of-school environments. Connected Science Learning, 11 Retrieved from www.csl.nsta. org/2019/07/the-common-instrument-suite.

Sprangers, M., \& Hoogstraten, J. (1989). Pretesting effects in retrospective pretestposttest designs. Journal of Applied Psychology, 74(2), 265-272. https://doi. org/10.1037/0021-9010.74.2.265

Stets, J. E., Brenner, P. S., Burke, P. J., \& Serpe, R. T. (2017). The science identity and entering a science occupation. Social Science Research, 64, 1-14. https://doi. org/10.1016/j.ssresearch.2016.10.016.

Tai, R. H., Liu, C. Q., Maltese, A. V., \& Fan, X. (2006). Planning early for careers in science. Science, 312(5777), 1143-1144. https://doi.org/10.1126/science. 1128690.

Tan, E., Barton, A. C., Kang, H., \& O'Neill, T. (2013). Desiring a career in STEMrelated fields: how middle school girls articulate and negotiate identities-inpractice in science: middle school girls' narrated and embodied identities-inpractice. Journal of Research in Science Teaching, 50(10), 1143-1179. https:// doi.org/10.1002/tea.21123

The Aspen Institute, \& Boston Consulting Group. (2018). Social, emotional, and academic development field landscape analysis: Narrative (pp. 1-188) Retrieved from https://www.aspeninstitute.org/events/introducing-the-socialemotional-and-academic-development-field-landscape-analysis/.

The Business Roundtable, \& Change the Equation. (2014). Solving the skills gap Retrieved from http://changetheequation.org/sites/default/files/Solving_the_ Skills_Gap.pdf.

The White House. (2009). President Obama launches "educate to innovate" campaign for excellence in science, technology, engineering \& math (STEM) education Retrieved June 7, 2019, from whitehouse.gov website: https:// obamawhitehouse.archives.gov/the-press-office/president-obama-launcheseducate-innovate-campaign-excellence-science-technology-en.

Tyler-Wood, T., Ellison, A., Lim, O., \& Periathiruvadi, S. (2012). Bringing up girls in science (BUGS): The effectiveness of an afterschool environmental science program for increasing female students' interest in science careers. Journal of 
Science Education and Technology, 21(1), 46-55. https://doi.org/10.1007/ s10956-011-9279-2

Vallett, D. B., Lamb, R., \& Annetta, L. (2018). After-school and informal STEM projects: the effect of participant self-selection. Journal of Science Education and Technology, 27(3), 248-255. https://doi.org/10.1007/s10956-017-9721-1.

Vandell, D. L. (2013). Afterschool program quality and student outcomes: reflections on positive key findings on learning and development from recent research. In W. S. White \& T. K. Peterson (Eds.), Expanding minds and opportunities: Leveraging the power of afterschool and summer learning for student success Retrieved from https://www.expandinglearning.org/ expandingminds/article/afterschool-program-quality-and-student-outcomesreflections-positive-key.

VanLeuvan, P. (2004). Young women's science/mathematics career goals from seventh grade to high school graduation. The Journal of Educational Research, 97(5), 248-268. https://doi.org/10.3200/JOER.97.5.248-268.

Venville, G., Rennie, L., Hanbury, C., \& Longnecker, N. (2013). Scientists reflect on why they chose to study science. Research in Science Education, 43(6), 22072233. https://doi.org/10.1007/s11165-013-9352-3.

Wang, X. (2013). Why students choose STEM majors: motivation, high school learning, and postsecondary context of support. American Educational Research Journal, 50(5), 1081-1121. https://doi.org/10.3102/ 0002831213488622

Weinburgh, M. (1995). Gender differences in student attitudes toward science: a meta-analysis of the literature from 1970 to 1991. Journal of Research in Science Teaching, 32(4), 387-398. https://doi.org/10.1002/tea.3660320407.

Wulf, R., Hinko, K., \& Finkelstein, N. (2013). Promoting children's agency and communication skills in an informal science program. AIP Conference Proceedings, 1513(430), 430-433. https://doi.org/10.1063/1.4789744.

Wulf, R., Mayhew, L. M., Finkelstein, N. D., Singh, C., Sabella, M., \& Rebello, S. (2010). Impact of informal science education on Children's attitudes about science (pp. 337-340). https://doi.org/10.1063/1.3515238.

Young, J. R., Ortiz, N., \& Young, J. L. (2017). STEMulating interest: a meta-analysis of the effects of out-of-school time on student STEM interest. International Journal of Education in Mathematics, Science and Technology, 5(1), 62. https:// doi.org/10.18404/ijemst.61149.

\section{Publisher's Note}

Springer Nature remains neutral with regard to jurisdictional claims in published maps and institutional affiliations.

\section{Submit your manuscript to a SpringerOpen ${ }^{\circ}$ journal and benefit from:}

- Convenient online submission

- Rigorous peer review

- Open access: articles freely available online

- High visibility within the field

- Retaining the copyright to your article

Submit your next manuscript at $\boldsymbol{\nabla}$ springeropen.com 